Article

\title{
Ceria: Recent Results on Dopant-Induced Surface Phenomena ${ }^{\dagger}$
}

\author{
Nicole Knoblauch ${ }^{1}$, Heike Simon ${ }^{1}$, Lars Dörrer ${ }^{2}$, Daniel Uxa ${ }^{2}$, Stefan Beschnitt ${ }^{3}$, \\ Peter Fielitz $^{2, *}$, Jens Wendelstorf ${ }^{2}{ }^{(D)}$, Karl-Heinz Spitzer ${ }^{2}$, Martin Schmücker ${ }^{1}$ and \\ Günter Borchardt ${ }^{2}$ \\ 1 Deutsches Zentrum für Luft- und Raumfahrt, Institut für Werkstoff-Forschung, Linder Höhe, \\ D-51147 Köln, Germany; Nicole.Knoblauch@dlr.de (N.K.); Heike.Simon@dlr.de (H.S.); \\ martin.schmuecker@dlr.de (M.S.) \\ 2 Institut für Metallurgie, Technische Universität Clausthal, Robert-Koch-Str. 42, \\ D-38678 Clausthal-Zellerfeld, Germany; lars.doerrer@tu-clausthal.de (L.D.); \\ daniel.uxa@tu-clausthal.de (D.U.); jens.wendelstorf@tu-clausthal.de (J.W.); \\ karl.heinz.spitzer@tu-clausthal.de (K.-H.S.); guenter.borchardt@tu-clausthal.de (G.B.) \\ 3 Institut für physikalische Chemie, RWTH Aachen University, Landoltweg 2, D-52074 Aachen, Germany; \\ stefan.beschnitt@rwth-aachen.de \\ * Correspondence: peter.fielitz@tu-clausthal.de; Tel.: +49-5323-72-2634 \\ + Dedicated to Professor Ilan Riess on the occasion of his 75th birthday.
}

Received: 27 September 2017; Accepted: 27 October 2017; Published: 8 November 2017

\begin{abstract}
Redox studies on dense zirconia-doped ceria pellets were carried out by thermogravimetric investigations and dilatometry. Up to $1600 \mathrm{~K}$ reduction parameters determined by both methods correspond to each other. At higher temperatures, however, thermogravimetry overestimates the degree of reduction since mass loss is not only due to oxygen exsolution but also to selective evaporation of $\mathrm{CeO}_{2}$ whose vapour pressure is considerably higher than that of $\mathrm{ZrO}_{2}$. As a consequence surface segregation of zirconia occurs in $(\mathrm{Ce}, \mathrm{Zr}) \mathrm{O}_{2-\delta}$ pellets leading to a porous surface zone of $\mathrm{Ce}_{2} \mathrm{Zr}_{2} \mathrm{O}_{7}$ pyrochlore which gradually grows in thickness. Surface enrichment of zirconia is detrimental for splitting $\mathrm{CO}_{2}$ or $\mathrm{H}_{2} \mathrm{O}$ since re-oxidation temperatures of $(\mathrm{Ce}, \mathrm{Zr}) \mathrm{O}_{2-\delta}$ are known to be shifted towards lower temperatures with increasing $\mathrm{ZrO}_{2}$ content. Thus, very harsh reduction conditions should be avoided for the $(\mathrm{Ce}, \mathrm{Zr}) \mathrm{O}_{2-\delta}$ redox system. The kinetics investigations comprised the high temperature reduction step $(T \cong 1600 \mathrm{~K})$ and the "low" temperature oxidation reaction with a carbon dioxide atmosphere $(T \cong 1000 \mathrm{~K}$ ). The reduction kinetics (at around $1600 \mathrm{~K}$ and an oxygen activity of $7 \times 10^{-4}$ in the gas phase) directly yield the (reduction) equilibrium exchange rate of oxygen in the order of $10^{-7} \mathrm{~mol} \cdot \mathrm{O} /\left(\mathrm{cm}^{3} \cdot \mathrm{s}\right)$ as the kinetics are surface controlled. The oxidation step at around $1000 \mathrm{~K}$, however, occurs in the mixed control or in the diffusion control regime, respectively. From oxygen isotope exchange in combination with SIMS depth profiling oxygen exchange coefficients, $K$, and oxygen diffusivities, $D$, were determined for so-called equilibrium experiments as well as for non-equilibrium measurements. From the obtained values for $K$ and $D$ the (oxidation) equilibrium exchange rates for differently doped ceria samples were determined. Their dependency on the oxygen activity and the nature and the concentrations of a tetravalent dopant $(\mathrm{Zr})$ and trivalent dopants $(\mathrm{La}, \mathrm{Y}, \mathrm{Sm})$ could be semi-quantitatively rationalised on the basis of a master equation for the equilibrium surface exchange rate.
\end{abstract}

Keywords: ceria; thermal expansion; chemical expansion; oxygen diffusion; oxygen surface exchange

\section{Introduction}

Renewable energy technologies are crucial in view of global warming and limited fossil fuel resources. One promising solution for the environmental-friendly production of essential components 
$\left(\mathrm{H}_{2}, \mathrm{CO}\right)$ for synthetic fuels is the application of thermochemical cycles with concentrated solar energy as heat source [1]. The core of such thermochemical process is a redox material which allows water or carbon dioxide splitting at feasible temperature conditions. Cerium oxide is a very attractive redox material for such thermochemical cycles due to its redox thermodynamics and fast redox kinetics.

In the first endothermic step of a ceria-based thermochemical cycle, $\mathrm{CeO}_{2}$ is partially reduced to $\mathrm{CeO}_{2-\delta}$. In the second step $\mathrm{Ce}^{3+}$ re-oxidizes exothermically to $\mathrm{Ce}^{4+}$ in the presence of $\mathrm{H}_{2} \mathrm{O} / \mathrm{CO}_{2}$ to produce $\mathrm{H}_{2} / \mathrm{CO}$ (see, e.g., [1-4]).

$$
\begin{gathered}
\mathrm{CeO}_{2} \rightarrow \mathrm{CeO}_{2-\delta}+\frac{\delta}{2} \mathrm{O}_{2} \\
\mathrm{CeO}_{2-\delta}+\delta\left\{\mathrm{H}_{2} \mathrm{O} / \mathrm{CO}_{2}\right\} \rightarrow \mathrm{CeO}_{2}+\delta\left\{\mathrm{H}_{2} / \mathrm{CO}\right\}
\end{gathered}
$$

Besides thermodynamic and kinetic reasons, the $\mathrm{CeO}_{2} / \mathrm{CeO}_{2-\delta}$ redox system is attractive from a technical point of view since $\mathrm{CeO}_{2-\delta}$ is structurally closely related to $\mathrm{CeO}_{2}$. Hence, the redox reaction of ceria is a gradual oxygen exsolution/incorporation process rather than true phase transformation. Thus, virtually no nucleation barriers exist and only minor volume changes occur during the reduction/oxidation cycle. From these reasons $\mathrm{CeO}_{2}$-based redox materials are promising for reactive ceramic bodies (beads, foams, honeycomb structures).

The reducibility of ceria can be improved by doping with zirconia due to an increase of the equilibrium $p_{\mathrm{O}_{2}}$ at a given temperature [5-12]. The enhancement of reducibility implies an alteration of the respective redox thermodynamics. In comparison to un-doped ceria the redox reaction of $\mathrm{Zr}$ doped ceria reveals a lower enthalpy and entropy [6,9-12].

In the system $\mathrm{Ce}-\mathrm{Zr}-\mathrm{O}$ different phases such as fluorite-type $(\mathrm{Ce}, \mathrm{Zr}) \mathrm{O}_{2-\delta}$ solid solutions, tetragonally distorted $\mathrm{ZrO}_{2}$-rich fluorite structures or pyrochlore $\mathrm{Ce}_{2} \mathrm{Zr}_{2} \mathrm{O}_{7}$ occur depending on $\mathrm{Zr} / \mathrm{Ce}$ ratio, $p_{\mathrm{O}_{2}}$, and temperature [13-17]. Pyrochlore formation is assumed to result in lower redox entropy since possible site occupancies of oxygen vacancies are limited with respect to oxygen vacancy sites in the fluorite structure of pure ceria [17-21]. Although stoichiometry suggests that pyrochlore formation needs a balanced $\mathrm{Zr} / \mathrm{Ce}$ ratio, Shah et al. predict pyrochlore-type clusters in Ce-rich compositions [6]. Thus, a composition of $\mathrm{Ce}_{0.81} \mathrm{Zr}_{0.19} \mathrm{O}_{1.9}$ was considered as $\left(\mathrm{CeO}_{2}\right)_{0.62}\left(\mathrm{Ce}_{2} \mathrm{Zr}_{2} \mathrm{O}_{7}\right)_{0.095}$. Takacs et al. [12] showed that redox enthalpy and entropy changes caused by $\mathrm{Zr}$ incorporation into ceria clearly affect the maximum temperature of water splitting $\left(\mathrm{CeO}_{1.95}: T<950{ }^{\circ} \mathrm{C}, \mathrm{Ce}_{0.95} \mathrm{Zr}_{0.05} \mathrm{O}_{1.95}\right.$ : $T<700{ }^{\circ} \mathrm{C}, \mathrm{Ce}_{0.80} \mathrm{Zr}_{0.20} \mathrm{O}_{1.95}: \mathrm{T}<200{ }^{\circ} \mathrm{C}$ ). Thermodynamic analyses by Hao et al. [11] reveal that the optimum zirconia content with respect to thermochemical fuel production is $15-20 \%$, while Takacs et al. [12] analyzing solar-to-fuel efficiencies draw the conclusion that energy savings by reduction of zirconia-doped ceria are overcompensated by necessary additional energy inputs resulting from less favourable re-oxidation with $\mathrm{H}_{2} \mathrm{O}$. Because of the importance of ceria and ceria-zirconia materials in automotive catalysis related questions were already discussed in earlier publications (see, e.g., [22]) and were recently summarized in review articles (see, e.g., [23]).

In general, redox kinetics of ceria-based materials is either controlled by surface exchange reactions or by bulk transport of oxygen. Previous studies of reaction kinetics comprise oxygen isotope exchange in chemical equilibrium and relaxation experiments based on oxygen potential changes. Depending on the microstructure of the sample material used in the different studies, the respective authors derived surface exchange coefficients, $K$, or diffusivities, $D$, of oxygen, or both of them [24-30].

There is also a considerable amount of comprehensive literature on the general relation between the tracer parameters, $K^{*}$ and $D^{*}$, and the chemical parameters, $\widetilde{K}$ and $\widetilde{D}$, (see, e.g., [31,32] and references therein). In the framework of the current investigation the standard phenomenological treatment could recently be extended $[33,34]$. Because of the open questions on the nature of the $K-D$ correlation we will only consider publications which present data for both $K$ and $D$ and will not discuss other, though interesting, studies like electrical conductivity measurements where electrodes are used and which, at best, supply the oxygen ion conductivity (which would yield the oxygen self-diffusivity) but no information on the surface exchange coefficient (see, e.g., [35]) nor, respectively, electrical 
conductivity relaxation studies which yielded only surface exchange coefficients but no diffusion coefficients (see, e.g., [36]).

In this joint publication we will not review the literature on ceria in its entirety, but firstly we present some very recent findings on degradation via selective sublimation of ceria occurring in $\mathrm{Zr}$-doped ceria. Next, an application of our phenomenological treatment of oxygen exchange kinetics is given as well as a first comparative study of oxygen exchange from an $\mathrm{O}_{2}$ atmosphere and from a $\mathrm{CO}_{2}$ atmosphere, respectively.

\section{Sample Preparation}

$\mathrm{CeO}_{2}$ and doped $\mathrm{CeO}_{2}$ powders were synthesized by the Pechini method [37]. Therefore, $\mathrm{Ce}\left(\mathrm{NO}_{3}\right)_{3} \cdot 6 \mathrm{H}_{2} \mathrm{O}$ (Alfa Aesar 99.99\%) and salts of doping Elements $\mathrm{Zr}$, Sm and $\mathrm{Y}\left(\mathrm{ZrO}(\mathrm{Cl})_{2} \cdot 8 \mathrm{H}_{2} \mathrm{O}\right.$, $\mathrm{Sm}\left(\mathrm{NO}_{3}\right)_{3} \cdot 6 \mathrm{H}_{2} \mathrm{O}, \mathrm{Y}\left(\mathrm{NO}_{3}\right)_{3} \cdot 6 \mathrm{H}_{2} \mathrm{O}, 99.9 \%$ Alfa Aesar) were dissolved in demineralized water in the corresponding concentrations and citric acid (VWR chemicals) and ethylene glycol (VWR chemicals) were added in a molar ratio of 1:2:3 (cations:citric acid:ethylene glycol). The obtained mixture was stirred at $373 \mathrm{~K}$ for $1 \mathrm{~h}$. A stepwise increase of the temperature up to $473 \mathrm{~K}$ resulted in a concentrated solution due to water evaporation. Finally, a viscous yellow gel was formed by polyesterification.

This gel was heated to $723 \mathrm{~K}$ for pyrolysis of organic species. The product was calcined in an electrical furnace at $1023 \mathrm{~K}$ in air for $2 \mathrm{~h}$ to remove any remaining carbonaceous species. To prepare disc-shaped powder compacts ( $\varnothing 13.4 \mathrm{~mm}$, thickness $h=1.47 \mathrm{~mm}$ or $0.87 \mathrm{~mm}$, respectively) and bar-shaped compacts $(50 \times 5 \times 3 \mathrm{~mm})$ the powder was uniaxially cold-pressed at 283 or $200 \mathrm{MPa}$, respectively. After sintering at $1923 \mathrm{~K}$ for $2 \mathrm{~h}$ the ceria-based ceramics had $93-95 \%$ of theoretical density. While the concentration of lanthanum $(\approx 0.2$ at $\%)$ has to be taken into consideration as trivalent dopant the other impurities were mutually compensating and in total below about 0.09 at $\%$.

Beside X-ray diffraction (HT-XRD D8 Advance A25, Bruker, Billerica, MA, USA) the powder compacts were analysed by scanning electron microscopy (SEM, Ultra 55 FEG, Carl Zeiss, Oberkochen, Baden-Württemberg, Germany) equipped with an energy-dispersive X-ray spectroscopy (EDS) system (INCA-Software, Version 5.0, Oxford Instruments, Abingdon, Oxgordshire, England) and by transmission electron microscopy (Philips Tecnai F30, Hillsboro, OR, USA).

Polycrystalline $\mathrm{Ce}_{0.85} \mathrm{Zr}_{0.15} \mathrm{O}_{2}$ rods were reduced in a tube furnace (TA Instruments) under low total pressure at high temperature for different lengths of time. The low pressure $\left(\sim 4 \times 10^{-9} \mathrm{bar}\right)$ was realized by a turbomolecular pump (HiCube 80Eco, Pfeiffer Vacuum, Aßlar, Hessen, Germany). The turbomolecular pump was working permanently over the entire experiment to remove the released oxygen of the sample. By use of a vacuum gauge (Penningvac, Oerlikon Leybold Vacuum, Köln, Nordrhein-Westfalen, Germany) the pressure was recorded continuously. To avoid reactions with the alumina furnace tube the sample rods were placed on carriers coated with platinum foil. The temperature during the redox reaction was determined by thermocouples located close to the sample rod. A reduction temperature of $1683 \mathrm{~K}(6 \mathrm{~K} / \mathrm{min})$ was hold for different times of $2.5 \mathrm{~h}, 5 \mathrm{~h}$ and $15 \mathrm{~h}$ before cooling down $(-6 \mathrm{~K} / \mathrm{min})$ under vacuum conditions.

\section{Degradation of $(\mathrm{Ce}, \mathrm{Zr}) \mathrm{O}_{2}$ Redox Ceramics by Selective Sublimation}

In a previous study on redox characteristics of ceria the results suggest sublimation of ceria at high temperature above $1660 \mathrm{~K}$ and low $p_{\mathrm{O}_{2}}\left((2-7) \times 10^{-9}\right.$ bar $)$ [38]. In that study thermal and chemical volume changes were investigated by high-resolution dilatometry using dense $\mathrm{CeO}_{2}$ rods. The chemical volume change of ceria redox ceramics is caused by the change of ionic radii $\mathrm{Ce}^{4+}, 97 \mathrm{pm}$ vs. $\mathrm{Ce}^{3+}, 114 \mathrm{pm}[39]$, going along with the formation of oxygen vacancies providing charge neutrality and by repulsion of defects and their atomic neighbours. The formation of oxygen vacancies alone would result in a lattice contraction, but this effect is overcompensated by the formation of bigger $\mathrm{Ce}^{3+}$ ions, thus leading to gradual increase of $\mathrm{CeO}_{2-\delta}$ lattice constants with increasing $\delta$ value $[40,41]$. 
The suboxide parameter $\delta$ can be determined from dilatometric data (green curve in Figure 1a) according to

$$
\frac{\Delta a}{a}=\frac{\Delta L}{L}=(0.0726 \pm 0.00335) \cdot \delta
$$

where $a$ is the lattice constant and $L$ is the sample length [42].

On the other hand, $\delta$ can be calculated from gravimetric data (orange curve in Figure 1a)

$$
\delta=\frac{M \cdot \Delta m}{M_{O} \cdot m_{s}}
$$

where $M$ is the molar mass of $\mathrm{Ce}_{1-x} \mathrm{M}_{x} \mathrm{O}_{2}, M_{O}$ is the molar mass of oxygen, $m_{s}$ is the sample mass in the fully oxidized state and $\Delta m$ is the mass loss.

As long as the reduction temperatures are below $1600 \mathrm{~K}$ the calculated $\delta$ values based on chemical expansion and on the mass loss are virtually the same. Above $1600 \mathrm{~K}$, however, these two $\delta$ values gradually diverge. With increasing temperatures the dilatometric data (Equation (3)) yield lower apparent $\delta$ values than the gravimetric data (Equation (4)). Thus, it can be assumed that the observed weight loss of ceria occurring at high temperatures and low pressure is not only the result of chemical reduction but is superimposed by sublimation effects. Sublimation of ceria under such conditions is obvious since the vapour pressure of ceria is high in comparison to other refractory compounds (Figure 1b).

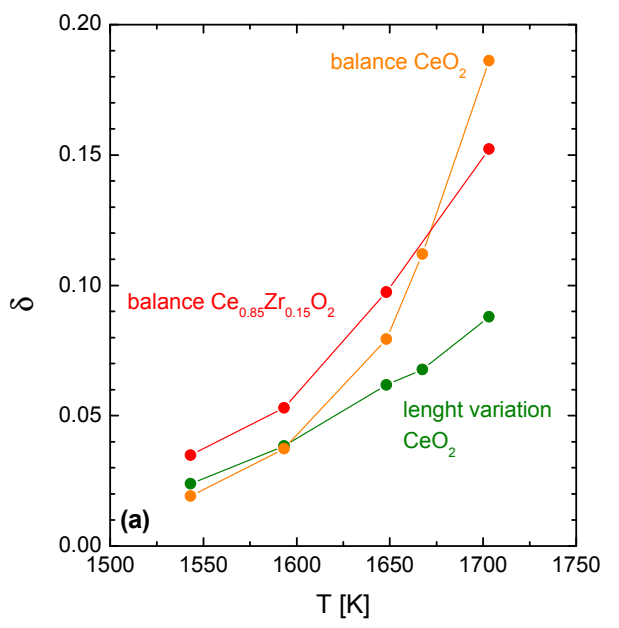

(a)

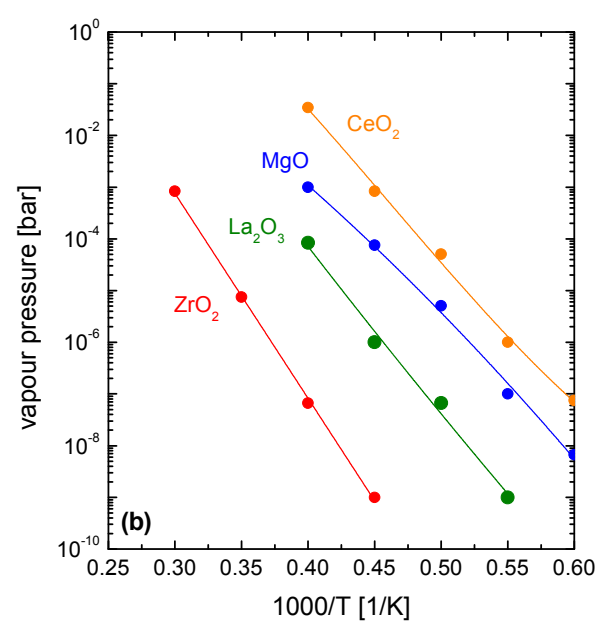

(b)

Figure 1. (a) Calculated $\delta$ values based on chemical expansion (green) and mass loss (orange) of $\mathrm{CeO}_{2}$ [38] and mass loss of $\mathrm{Ce}_{0.85} \mathrm{Zr}_{0.15} \mathrm{O}_{2}$ (red) as a function of temperature at $p_{\text {total }}=4 \times 10^{-9}$ bar; (b) Vapour pressures of various oxides as a function of the reciprocal temperature [43].

In the present work the influence of ceria sublimation is investigated for $\mathrm{Zr}$ doped ceria ceramics. For that, $\mathrm{Zr}$ doped ceria samples $\left(\mathrm{Ce}_{0.85} \mathrm{Zr}_{0.15} \mathrm{O}_{2}\right)$ were reduced under the above mentioned temperature/vacuum conditions. Based on the mass loss data, suboxide parameters $\delta$ were calculated according to Equation (4) (red curve in Figure 1a). At $1550 \mathrm{~K}$ and $1600 \mathrm{~K}$ the mass loss of $\mathrm{Ce}_{0.85} \mathrm{Zr}_{0.15} \mathrm{O}_{2}$ is somewhat higher than determined for pure $\mathrm{CeO}_{2}$ which corresponds to the beneficial effect of $\mathrm{Zr}$ doping in terms of thermochemical reduction. Above $1600 \mathrm{~K}$, deviation between mass-derived apparent $\delta$ values of $\mathrm{Ce}_{0.85} \mathrm{Zr}_{0.15} \mathrm{O}_{2}$ and expansion-derived $\delta$ values of $\mathrm{CeO}_{2}$ gradually increases. Hence, sublimation effects at high temperatures can be assumed also for $\mathrm{Ce}_{0.85} \mathrm{Zr}_{0.15} \mathrm{O}_{2}$ compositions. At $1700 \mathrm{~K}$, however, sublimation of $\mathrm{Ce}_{0.85} \mathrm{Zr}_{0.15} \mathrm{O}_{2}$ is less with respect to pure $\mathrm{CeO}_{2}$.

Ceria evaporation from $\mathrm{Ce}_{0.85} \mathrm{Zr}_{0.15} \mathrm{O}_{2}$ redox ceramics was subsequently analysed in more detail by SEM, TEM, EDS and XRD methods. Ceria evaporation from $(\mathrm{Ce}, \mathrm{Zr}) \mathrm{O}_{2}$ solid solutions is of particular 
interest since vapour pressures of $\mathrm{CeO}_{2}$ and $\mathrm{ZrO}_{2}$ are known to differ by 5 orders of magnitude [43]. Thus, it can be anticipated that evaporation of ceria gradually may go along with segregation effects. To study accelerated sublimation effects, $\mathrm{Zr}$ doped ceria samples $\left(\mathrm{Ce}_{0.85} \mathrm{Zr}_{0.15} \mathrm{O}_{2}\right)$ were subjected to high temperature /low $p_{\mathrm{O}_{2}}$ conditions $\left(T=1683 \mathrm{~K}, p_{\text {total }}=4 \times 10^{-9}\right.$ to $10^{-8}$ bar) for dwell times of $2.5 \mathrm{~h}, 5 \mathrm{~h}$ and $15 \mathrm{~h}$.

Figures 2 and 3 show SEM images and the time dependence of the thickness of the porous zone, respectively, of a $\mathrm{Ce}_{1-x} \mathrm{Zr}_{x} \mathrm{O}_{2}$ sample $(x=0.15)$ which was reduced at $1683 \mathrm{~K}$ for up to $15 \mathrm{~h}$ at $p_{\text {total }}=4 \times 10^{-9}$ bar. After firing $\mathrm{Ce}_{0.85} \mathrm{Zr}_{0.15} \mathrm{O}_{2}$ samples under the aforementioned conditions obvious microstructural changes become visible: The initially polished sample has developed a spongy surface (Figure 2a). A SEM image of the cross section of the sample depicted a porous surface zone (Figure $2 b$ ). It is noteworthy that a sharp transition between the dense parent ceramic material and the porous surface zone occurs rather than a gradual transition. Surface microstructures of the $\mathrm{Ce}_{0.85} \mathrm{Zr}_{0.15} \mathrm{O}_{2}$ samples fired for 2.5 and $5 \mathrm{~h}$ are similar, but the thicknesses of the spongy zones are correspondingly smaller. A sublimation zone of $1 \mu \mathrm{m}$ thickness already exists at $t=0$ which is due to the fact that sublimation starts already during heating up.

Microchemical analyses of samples of 2.5 and $5 \mathrm{~h}$ evaporation treatments were performed by EDS analyses. According to the size of the transition region and the required spatial EDS resolution TEM-EDS was employed for the $2.5 \mathrm{~h}$ sample (see Figure 4) while SEM-EDS was appropriate for the later evaporation stage. Elemental mapping by TEM-EDS (Figure $4 \mathrm{~b}$ ) shows that the porous zone formed after $2.5 \mathrm{~h}$ heat treatment consists of $90 \% \mathrm{ZrO}_{2}$ while the composition of the bulk material is virtually unaffected $\left(85 \mathrm{wt} \% \mathrm{CeO}_{2}, 15 \mathrm{wt} \% \mathrm{ZrO}_{2}\right)$. Between the zirconia-rich spongy surface region and the unaffected bulk material a small interlayer of intermediate chemical composition $\left(50-60 \% \mathrm{CeO}_{2}\right.$, green rim zone in Figure $4 \mathrm{~b}$ ) was detected. This composition corresponds approximately to the $\mathrm{Ce} / \mathrm{Zr}$ ratio of a pyrochlore phase $\left(\mathrm{Ce}_{2} \mathrm{Zr}_{2} \mathrm{O}_{7}\right)$ [17]. Sporadically, the $\mathrm{Zr} / \mathrm{Ce}=1: 1$ composition occurs also within the spongy structure.

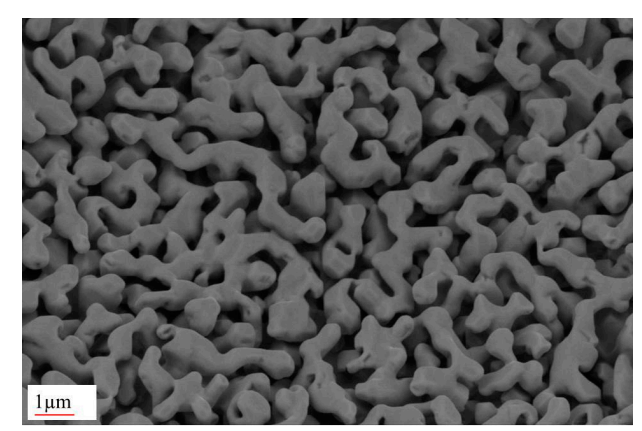

(a)

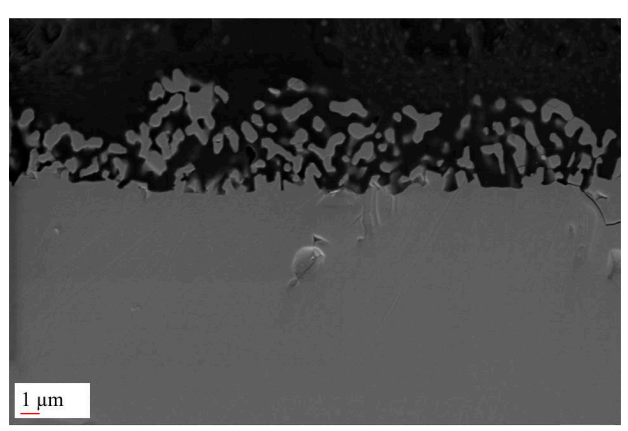

(b)

Figure 2. (a) SEM image of the surface of a $\mathrm{Ce}_{1-x} \mathrm{Zr}_{x} \mathrm{O}_{2}$ sample $(x=0.15)$ which was reduced at $1683 \mathrm{~K}$ for $15 \mathrm{~h}$ at $p_{\text {total }}=4 \times 10^{-9}$ bar; (b) SEM image of the cross section of the same sample. 


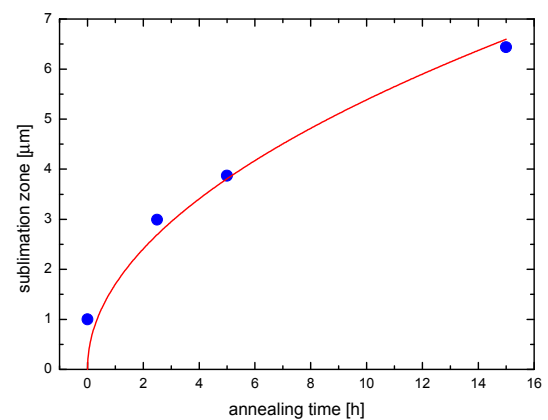

Figure 3. Thickness of the porous surface zone of $\mathrm{Ce}_{1-x} \mathrm{Zr}_{x} \mathrm{O}_{2}$ samples $(x=0.15)$ fired at $1683 \mathrm{~K}$ for different annealing times $\left(p_{\text {total }}=4 \times 10^{-9}\right.$ bar $)$.

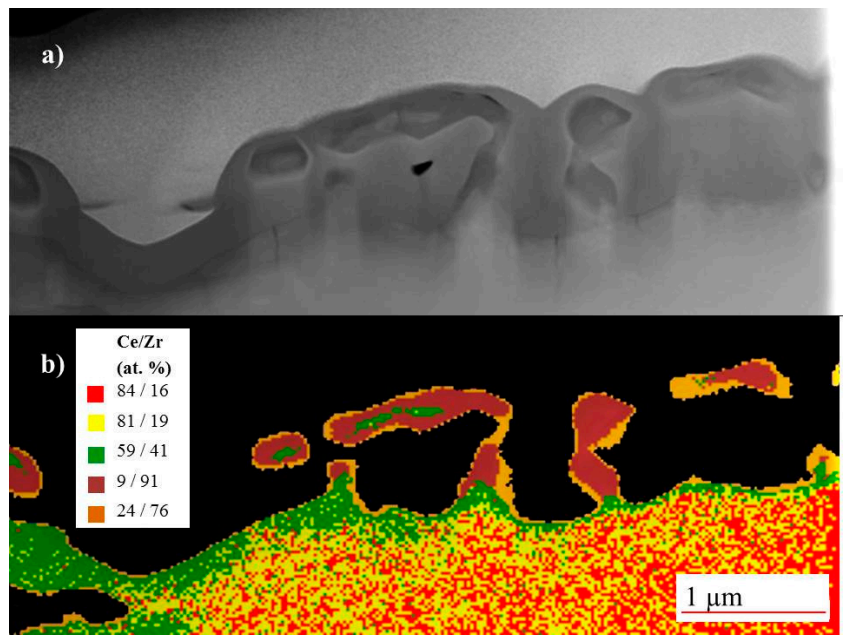

Figure 4. (a) TEM image (FIB-ablation) of a $\mathrm{Ce}_{1-x} \mathrm{Zr}_{x} \mathrm{O}_{2}$ sample sample reduced at $1683 \mathrm{~K}$ for $2.5 \mathrm{~h}$ $\left(p_{\text {total }}=4 \times 10^{-9}\right.$ bar $) ;($ b $)$ EDS mapping $(\mathrm{Ce} / \mathrm{Zr})$ where red $=(84 / 16)$, yellow $=(81 / 19)$, green $=(59 / 41)$, dark red $=(9 / 91)$, ochre $=(24 / 76)$.

After $5 \mathrm{~h}$ evaporation treatment a change in chemical composition is observed (Figure 5). Still, the composition of the dense material underneath the spongy zone is unaffected. All over the porous zone, however, $\mathrm{Ce} / \mathrm{Zr}=1: 1$ composition is found without an indication of further $\mathrm{Zr}$-enrichment towards the outer surface.

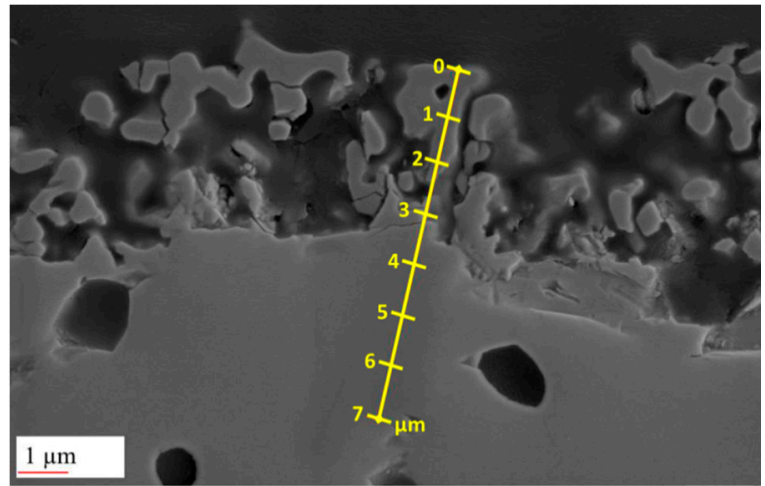

(a)

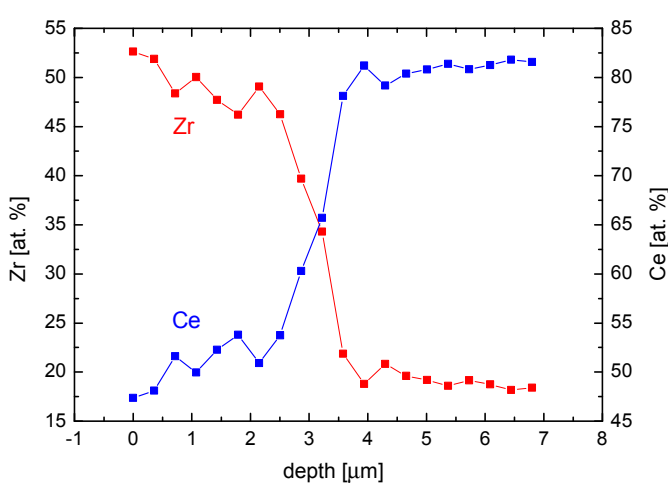

(b)

Figure 5. (a) SEM image of a cross section of a $\mathrm{Ce}_{0.85} \mathrm{Zr}_{0.15} \mathrm{O}_{2-\delta}$ sample rod reduced at $1683 \mathrm{~K}$ for $5 \mathrm{~h}$ $\left(p_{\text {total }}=4 \times 10^{-9}\right.$ bar); (b) Resulting Ce/ $\mathrm{Zr}$ ratio of the EDS line scan along the yellow line in (a). 
The data in Figure 3 suggets a kind of parabolic growth law and yields for the effective parabolic rate constant the value of $k(1683 \mathrm{~K}) \approx 4 \times 10^{-16} \mathrm{~m}^{2} / \mathrm{s}$. Taking into account the structure of this kind of constant, i.e., $k \approx\left|\Delta \mu_{\mathrm{CeO}_{2}} / R T\right| \cdot D_{\text {eff }}$, with typically $\left|\Delta \mu_{\mathrm{CeO}_{2}} / R T\right| \approx \ln (0.85 / 0.15) \approx 2$ according to Figure $5 \mathrm{~b}$ for an ideal $\mathrm{CeO}_{2}-\mathrm{ZrO}_{2}$ solid solution, it becomes obvious that the rate determining step is diffusion in the solid state with an effective diffusion coefficient $D_{\text {eff }} \leq 10^{-16} \mathrm{~m}^{2} / \mathrm{s}$, most probably indicating transport of the host cations via rapid diffusion paths (grain boundaries, interfaces) [44]. Here $\Delta \mu_{\mathrm{CeO}_{2}}$ is the difference of the chemical potential of ceria across the porous ceria-depleted surface zone, while $R$ and $T$ have the usual meaning. In this approximation any pyrochlore formation has been neglected, because the resulting further decrease of the ceria activity in the outermost layer would not significantly change the order of magnitude of $D_{\text {eff }}$, which is much higher than calculated cerium bulk diffusivities (see [45] and references therein).

More detailed information of newly formed phases in the porous zone was obtained by $\mathrm{X}$-ray diffraction. Figure 6 shows diffraction patterns of a $\mathrm{Ce}_{0.85} \mathrm{Zr}_{0.15} \mathrm{O}_{2}$ sample fired at $1683 \mathrm{~K}$ for $2.5 \mathrm{~h}$ and $15 \mathrm{~h}$ (blue, black) together with the $\mathrm{X}$-ray trace of the same sample after removing the porous surface zone by grinding (red) and the initial state (green). The XRD pattern after grinding unambiguously corresponds to the reduced solid solution of $\mathrm{Ce}_{0.85} \mathrm{Zr}_{0.15} \mathrm{O}_{2-\delta}$ while the sample after $15 \mathrm{~h}$ reduction, containing the spongy zone, displays additional diffraction peaks of the pyrochlore phase $\mathrm{Ce}_{2} \mathrm{Zr}_{2} \mathrm{O}_{7}$ plus faint peaks of $\mathrm{ZrO}_{2}$. In the earlier state after $2.5 \mathrm{~h}$ the diffraction peak assigned to the pyrochlore phase (higher diffraction angle) could be interpreted as double peak, where the peak on the right- hand side should contain a higher $\mathrm{Zr}$ concentration than $50 \mathrm{~mol} \%$. The diffraction pattern of the pyrochlore phase in general consists of a main pattern closely related to that of ceria plus additional superstructure peaks [17]. The reason for superstructure peaks is the lower symmetry of the $\mathrm{Ce}_{2} \mathrm{Zr}_{2} \mathrm{O}_{7}$ structure (space group $F d \overline{3} m$ ) with respect to $(\mathrm{Ce}, \mathrm{Zr}) \mathrm{O}_{2-\delta}(F m \overline{3} m)$ caused by cation and oxygen vacancy ordering (Figure 7). The main pattern of the superficial pyrochlore zone is close to the pattern of the parent $\mathrm{Ce}_{0.85} \mathrm{Zr}_{0.15} \mathrm{O}_{2-\delta}$ phase with a slight shift to higher diffraction angles.

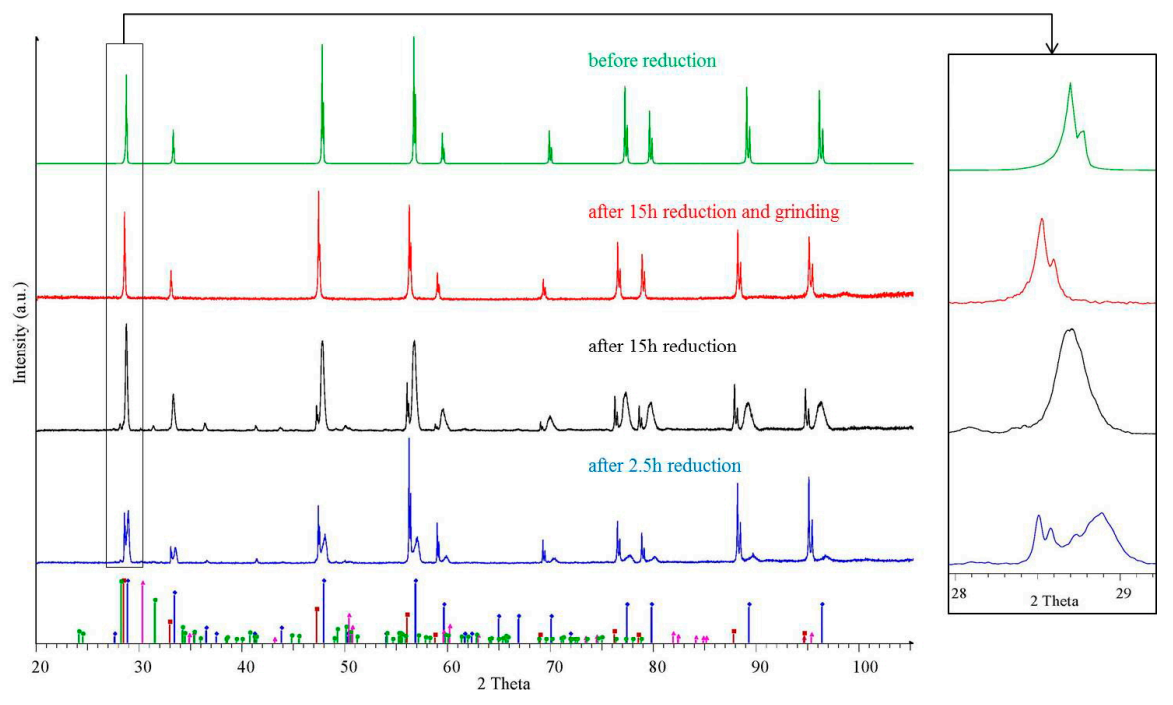

Figure 6. XRD pattern of a $\mathrm{Ce}_{0.85} \mathrm{Zr}_{0.15} \mathrm{O}_{2-\delta}$ sample rod reduced at $1683 \mathrm{~K}$ ( $p_{\text {total }}=4 \times 10^{-9}$ bar $)$ for $2.5 \mathrm{~h}$ (blue), for $15 \mathrm{~h}$ (black), after grinding (red) and before reduction in comparison to theoretical pattern of $\mathrm{ZrO}_{2}$ monoclinic (ICDD PDF-00-037-1484), $\mathrm{ZrO}_{2}$ tetragonal (ICDD PDF-00-050-1089), $\mathrm{Ce}_{2} \mathrm{Zr}_{2} \mathrm{O}_{7}$ (ICDD PDF-00-034-0394 lattice constant modified: $10.7312 \AA$ ) and $\mathrm{CeO}_{2}$ (ICDD PDF-00-034-0394 lattice constant modified: $5.43839 \AA$ ). 


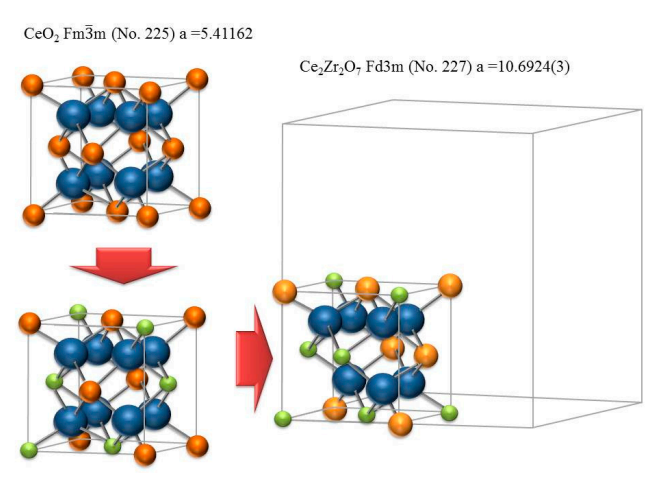

Figure 7. The unit cell of $\mathrm{CeO}_{2}$ in comparison to $1 / 8$ unit cell of pyrochlore $\mathrm{Ce}_{2} \mathrm{Zr}_{2} \mathrm{O}_{7}$ (blue $=$ oxygen, green $=\mathrm{Zr}^{+4}$, ochre $=\mathrm{Ce}^{+4}$, yellow $=\mathrm{Ce}^{+3}$ ).

The observed surface transformation phenomena may be explained according to the following scheme (Figure 8):

Stage 1 Selective evaporation of $\mathrm{CeO}_{2}$ from $\mathrm{Ce}_{0.85} \mathrm{Zr}_{0.15} \mathrm{O}_{2-\delta}$ results in the formation of a highly porous surface zone very rich $(\cong 90 \%)$ in $\mathrm{ZrO}_{2}$. The observation of superficial zirconia enrichment implies that diffusion of Ce cations from bulk to surface cannot keep up with $\mathrm{CeO}_{2}$ evaporation.

Stage 2 By interfacial reaction between the outer porous $\mathrm{ZrO}_{2}$ zone and the unaffected $\mathrm{Ce}_{0.85} \mathrm{Zr}_{0.15} \mathrm{O}_{2-\delta}$ parent phase an interlayer of $\mathrm{Ce}_{2} \mathrm{Zr}_{2} \mathrm{O}_{7}$ gradually forms. Early formation of a $\mathrm{Ce}_{2} \mathrm{Zr}_{2} \mathrm{O}_{7}$ interphase is frozen in (Figure 4).

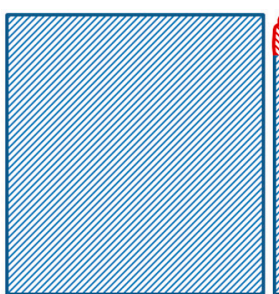

Starting

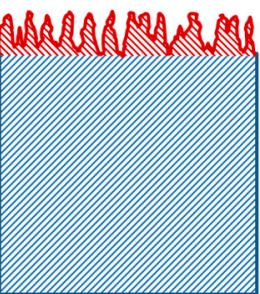

Stage 1

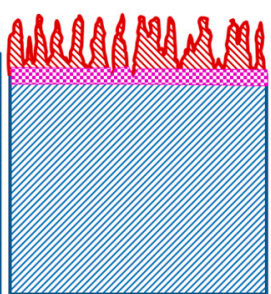

Stage 2

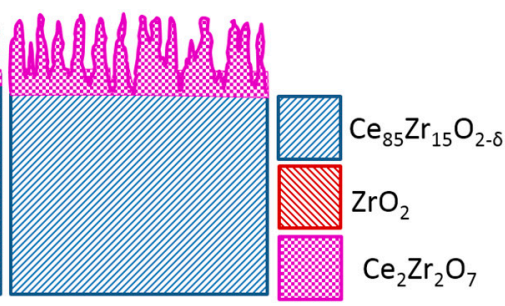

Stage 3

Figure 8. General scheme of the evaporation process during heating of $\mathrm{Ce}_{0.85} \mathrm{Zr}_{0.1} 5 \mathrm{O}_{2-\delta}$ under low oxygen partial pressure.

Stage 3 Growth of the $\mathrm{Ce}_{2} \mathrm{Zr}_{2} \mathrm{O}_{7}$ interlayer proceeds; due to lower $\mathrm{CeO}_{2}$ activity in $\mathrm{Ce}_{2} \mathrm{Zr}_{2} \mathrm{O}_{7}$ the evaporation rate of $\mathrm{CeO}_{2}$ decreases. By that, diffusion of $\mathrm{Ce}$ cations from bulk to surface may keep up with $\mathrm{CeO}_{2}$ evaporation. In this stage (represented in Figure 5) the spongy surface region gradually grows without changing its composition significantly. The assumption of a gradually decreasing evaporation rate with the formation of pyrochlore $\mathrm{Ce}_{2} \mathrm{Zr}_{2} \mathrm{O}_{7}$ is also supported by the development of the mass loss curves of $\mathrm{Ce}_{0.85} \mathrm{Zr}_{0.15} \mathrm{O}_{2}$ (red curve in Figure 1a) $\mathrm{Up}$ to $1650 \mathrm{~K}$ the temperature-dependent mass loss development of $\mathrm{Ce}_{0.85} \mathrm{Zr}_{0.15} \mathrm{O}_{2-\delta}$ and $\mathrm{CeO}_{2-\delta}$ (orange curve in Figure 1a) are very similar. At higher temperature, however, when the formation of $\mathrm{Ce}_{2} \mathrm{Zr}_{2} \mathrm{O}_{7}$ can be expected, mass loss of $\mathrm{Ce}_{0.85} \mathrm{Zr}_{0.15} \mathrm{O}_{2}$ ceramics is significantly lower than for the $\mathrm{CeO}_{2}$ reference material.

In view of thermochemical water splitting by means of $(\mathrm{Ce}, \mathrm{Zr}) \mathrm{O}_{2-\delta}$ redox reactions any surface enrichment of $\mathrm{ZrO}_{2}$ by preferential evaporation of the $\mathrm{CeO}_{2}$ compound is detrimental. Though pyrochlore $\mathrm{Ce}_{2} \mathrm{Zr}_{2} \mathrm{O}_{7}$ surface composition still may facilitate the reduction step, re-oxidation by water vapour virtually can be ruled out. Thermodynamic data from Zhou et al. [7] clearly show that water splitting temperatures for $(\mathrm{Ce}, \mathrm{Zr}) \mathrm{O}_{2-\delta}$ solid solutions under equilibrium conditions gradually shift towards lower temperatures with increasing $\mathrm{ZrO}_{2}$ content. For $\mathrm{Ce} / \mathrm{Zr}=1 / 1$ (pyrochlore composition) water splitting temperature is as low as $200^{\circ} \mathrm{C}$ and hence will be suppressed by kinetic reasons. 


\section{Surface Exchange and Bulk Diffusion of Oxygen from $\mathrm{O}_{2}$ and $\mathrm{CO}_{2}$ Atmospheres}

\subsection{Revision of the Standard Picture of the Oxygen Exchange Kinetics}

As early as 1996 Kilner et al. [46] showed that there is, for a large number of different oxide materials, a quite obvious correlation $K_{O}^{*} \propto\left(D_{O}^{*}\right)^{1 / 2}$ between the oxygen (tracer) surface exchange coefficient $K_{O}^{*}$ and the oxygen (tracer) diffusion coefficient $D_{O}^{*}$ (over almost 10 (!) orders of magnitude for $D_{O}^{*}$ ) for a number of perovskite compositions (with predominant electronic conductivity). Despite this empirical evidence it is assumed until to date [47-49], however, that $K_{O}$ and $D_{O}$ are independent parameters, each of which reflecting an independent microscopic mechanism. In Appendix A we show that this intuitive approach is not generally correct. According to the working equation derived in Appendix A (see Equation (A9)).

$$
\Re_{O}^{0}=\frac{c_{O}(0)}{w_{O}(0)} \cdot \frac{1}{\tau}
$$

the experimentally accessible time constant in a thermogravimetric relaxation (TGR) experiment, $\tau$, depends, for sufficiently thin sample slabs, no longer on the sample thickness, but only on the equilibrium exchange rate, $\Re_{O}^{0}$, the oxygen concentration, $c_{O}(0)$, and the thermodynamic factor, $w_{O}(0)$, at the surface $(x=0)$. Knowing (or making an intelligent guess about) the values of $c_{O}(0)$ and $w_{O}(0)$ one could thus determine the key parameter $\Re_{O}^{0}$ directly from a simple TGR run.

To test this conclusion TGR experiments were carried out in a STA 449 F3 Jupiter system (Netzsch, Selb, Germany). Disc-shaped samples (Ø $13.4 \mathrm{~mm}, 93 \%$ theoretical density) with two different thicknesses $\left(h_{1}=1.47 \mathrm{~mm}, h_{2}=0.87 \mathrm{~mm}\right)$ were prepared. The sample under investigation was placed on platinum foil on an alumina plate $(\varnothing 15 \mathrm{~mm})$.

For the reduction steps (at different high temperatures with a heating rate of $20 \mathrm{~K} / \mathrm{min}$ ) argon 5.0 was passed through the sample tube at a flow rate of $85 \mathrm{~mL} / \mathrm{min}$. The oxygen partial pressure of the employed gas atmosphere during the reduction step was calculated to be approximately $2 \times 10^{-4}$ bar by comparing the obtained (final) suboxide compositions with literature data given by Panlener [50]. The reduction temperatures were held for several hours for complete reduction. For the subsequent oxidation step the pellet was cooled $(50 \mathrm{~K} / \mathrm{min})$ to $800{ }^{\circ} \mathrm{C}$. After a dwell time of $5 \mathrm{~min}$ at $800{ }^{\circ} \mathrm{C}$ an argon-oxygen gas mixture was employed for $30 \mathrm{~min}\left(35 \mathrm{~mL} / \mathrm{min} \mathrm{O}_{2}, 50 \mathrm{~mL} / \mathrm{min}\right.$ Ar which corresponds to an oxygen partial pressure of about 0.4 bar). Subsequently, the gas was switched back to pure $\operatorname{Ar}\left(p_{\mathrm{O}_{2}}=2 \times 10^{-4}\right.$ bar) followed by a new reduction step. For data analysis the obtained mass loss curve was corrected by subtraction of a blank run (TG measurement without sample) to minimize device artefacts.

The results are shown in Figure 9 where the time dependence of the oxygen deficit parameter, $\delta(t)$, is plotted for a TGR experiment run at two different temperatures with two different sample thicknesses each time and the same starting difference of the chemical potential of oxygen between the gas phase and the sample. (Because of the rather short duration of the TGR experiments mass loss corrections due to evaporation were negligible.) 


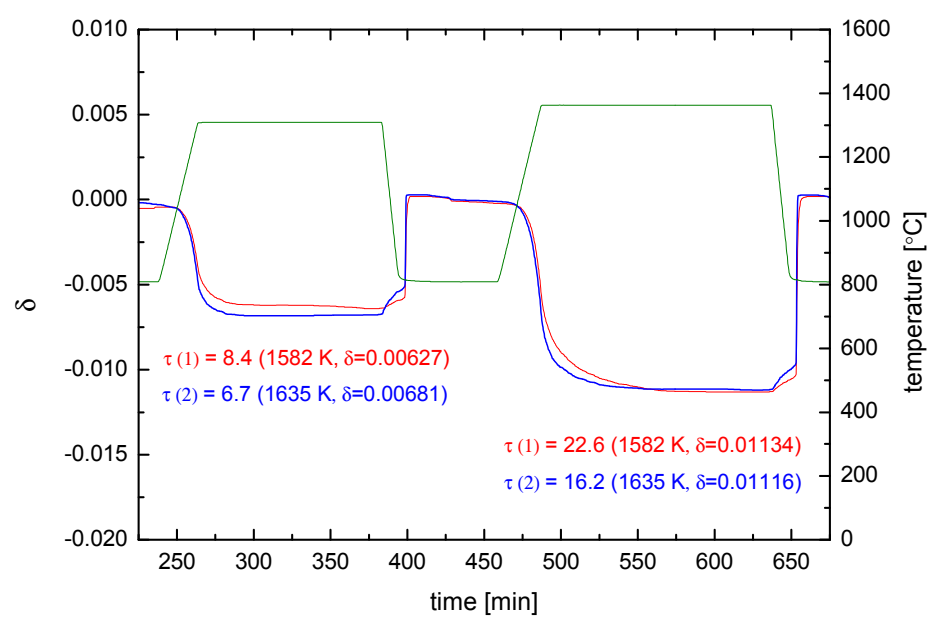

Figure 9. Reduction (and oxidation) kinetics at $1582 \mathrm{~K}$ and $1635 \mathrm{~K}$ of two un-doped $\mathrm{CeO}_{2}$ pellets (Ø $\left.13.4 \mathrm{~mm}, \rho / \rho_{\text {theor }}=0.93\right)$. Red: $\delta(t)$ for $h=1.47 \mathrm{~mm}, m=977.055 \mathrm{mg}$. Blue: $\delta(t)$ for $h=0.87 \mathrm{~mm}$, $m=586.083 \mathrm{mg}$. Green: $T(t)$.

In order to facilitate understanding the following section the reader is referred to Appendix B which gives a rapid overview on the requirements which have to be fulfilled for a TGR experiment to supply valid information.

For $\delta<<1$ one can use the corresponding bulk values in Equation (5), i.e., $c_{O}(0) \cong c_{O}$, and the thermodynamic factor can be approximated as follows with $\partial \ln \delta=n \partial \ln a_{\mathrm{O}_{2}}=2 n \partial \ln a_{O}, n=-1 / 5$ (after [50]) and $c_{O}=c_{O}^{\max }(1-\delta)$, where $c_{O}^{\max }$ is the oxygen concentration in the fully oxidized state. One obtains $w_{O}(0) \cong w_{O} \cong 2.5 / \delta$. From Figure $9 \delta(t \rightarrow \infty)$ and $\tau$ can be evaluated for the two samples (see Table 1), wherefrom $\Re_{O}^{0}$ is calculated via Equation (5) (for the reduction reaction).

Table 1. TGR (reduction kinetics) results at two different temperatures for $\mathrm{CeO}_{2-\delta}$ samples with different thicknesses and different (final) values of $\delta$.

\begin{tabular}{ccc}
\hline Temperature & Sample \#1 $\left(\boldsymbol{h}_{\mathbf{1}}=\mathbf{1 . 4 7} \mathbf{~ m m}\right)$ & Sample \#2 $\left(\boldsymbol{h}_{\mathbf{2}}=\mathbf{0 . 8 7} \mathbf{~ m m}\right)$ \\
\hline $1582 \mathrm{~K}$ & $\tau_{1}=8.35 \mathrm{~min}$ & $\tau_{2}=6.71 \mathrm{~min}$ \\
& $\delta_{1}=6.3 \times 10^{-3}$ & $\delta_{2}=6.81 \times 10^{-3}$ \\
$\left(\Re_{O}^{0}\right)_{1}=4.22 \times 10^{-7} \frac{\mathrm{mol} \cdot \mathrm{O}}{\mathrm{cm}^{3} \cdot \mathrm{s}}$ & $\left(\Re_{O}^{0}\right)_{2}=5.67 \times 10^{-7} \frac{\mathrm{mol} \cdot \mathrm{O}}{\mathrm{cm}^{3} \cdot \mathrm{s}}$ \\
\hline $1635 \mathrm{~K}$ & $\tau_{1}=22.55 \mathrm{~min}$ & $\tau_{2}=16.22 \mathrm{~min}$ \\
& $\delta_{1}=1.13 \times 10^{-2}$ & $\delta_{2}=1.12 \times 10^{-2}$ \\
$\left(\Re_{O}^{0}\right)_{1}=2.78 \times 10^{-8} \frac{\mathrm{mol} \cdot \mathrm{O}}{\mathrm{cm}^{3} \cdot \mathrm{s}}$ & $\left(\Re_{O}^{0}\right)_{2}=3.87 \times 10^{-7} \frac{\mathrm{mol} \cdot \mathrm{O}}{\mathrm{cm}^{3} \cdot \mathrm{s}}$ \\
\hline
\end{tabular}

A closer look at Table 1 reveals the following features:

(i) Check of $\tau \neq \tau(h)$ on the basis of Table B1 in Appendix B ( $\tau \propto h$ for surface controlled kinetics and $\tau \propto h^{2}$ for diffusion controlled kinetics, respectively):

$$
\begin{aligned}
& T=1582 K: \quad \tau_{1} / \tau_{2}=1.24 \quad \Leftrightarrow \quad h_{1} / h_{2}=1.7 \quad \Leftrightarrow \quad\left(h_{1} / h_{2}\right)^{2}=2.9 \\
& T=1635 K: \quad \tau_{1} / \tau_{2}=1.39 \quad \Leftrightarrow \quad h_{1} / h_{2}=1.7 \quad \Leftrightarrow \quad\left(h_{1} / h_{2}\right)^{2}=2.9
\end{aligned}
$$

This means (a) that $\tau$ does not depend on $h^{2}$ as for the diffusion control regime, and (b) that $\left(\tau_{1} / \tau_{2}\right)_{\text {theor }}=1$ is confirmed with a fairly small deviation: On the basis of a $10 \%$ relative experimental error on the $\tau$ values, the ratio of the experimental $\tau$ values has an error of $20 \%$. The negligible excess error may be due to the fact that the experiments were not yet fully surface exchange controlled but too close to the regime boundary at $L=0.3$ (see Figure A2 in Appendix A and Table B1 in Appendix B). 
(ii) (The experimental temperature interval $(53 \mathrm{~K})$ is too small to extract solid data for the activation enthalpy. The surprising behaviour of the $\Re_{O}^{0}$ values indicates that, however, the equilibrium exchange rate $\Re_{O}^{0}(T)$ depends probably only very weakly on temperature for a given $\Delta \mu_{\mathrm{O}_{2}}$.

Summarizing, this preliminary evaluation shows that further experimental work is necessary with even thinner samples and in a larger temperature window.

\subsection{Oxygen Exchange from $\mathrm{O}_{2}$ Atmospheres}

The most direct method of measuring oxygen self diffusivities and surface exchange coefficients in oxides is oxygen isotope exchange followed by Secondary Ion Mass Spectrometry (SIMS) depth profiling (IEDP) [51-53] or cross section line scan (IELS) as is shown schematically in Figure 10. For samples with a plane sheet geometry, as used in this work, the (tracer) diffusion coefficient, $D$, and the (tracer) surface exchange coefficient, $K$, of oxygen are defined by

$$
\left|j_{18_{O}}\right|=D\left(\left|\frac{\partial c_{18_{O}}}{\partial x}\right|\right)_{x=0}=K\left|c_{18_{O}}^{g}-c_{18_{O}}(x=0)\right|
$$

where $j_{18_{O}}$ is the oxygen tracer isotope (the ${ }^{18} \mathrm{O}$ isotope in this work) flux through the gas/solid interface, $c_{18_{O}}^{g}$ is the concentration of the oxygen isotope in the gas phase and $c_{18_{O}}$ the actual concentration of the oxygen isotope in the solid. For a semi-infinite homogeneous plane sample the analytical solution of the diffusion problem with this boundary condition and for constant parameters $K$ and $D$ is given by Crank [54] (the special notation of the solution was proposed by Fielitz and Borchardt [53]).

$$
\begin{aligned}
\frac{c_{18_{O}}(x, t)-c_{0_{18}}^{\infty}}{c_{18_{O}}^{8}-c_{18_{O}}^{\infty}}= & \operatorname{erfc}\left(\frac{x}{\sigma}\right)-\exp \left(2 \frac{x}{\sigma} \sqrt{\frac{t}{\tau}}+\frac{t}{\tau}\right) \operatorname{erfc}\left(\frac{x}{\sigma}+\sqrt{\frac{t}{\tau}}\right) \\
& \text { with } \sigma \equiv 2 \sqrt{D t} \text { and } \tau \equiv \frac{D}{K^{2}}
\end{aligned}
$$

where $c_{18_{O}}^{\infty}$ is the natural abundance of ${ }^{18} \mathrm{O}$ in the sample (at $x \rightarrow \infty$ ), $\sigma$ is the diffusion length of the tracer isotope and $\tau$ is the characteristic time constant to reach tracer isotope equilibrium at the gas/solid interface.

The polished (diamond down to $1 \mu \mathrm{m}$ ) and cleaned (ultrasonic cleaning in acetone followed by isopropanol) samples were annealed in an IR radiation heated furnace (Quad Elliptical, RI Controls/Research Incorporated, Minneapolis, MN, USA) which allows fast heating rates up to 100 $\mathrm{K} / \mathrm{s}$ in the temperature range between 300 and $900{ }^{\circ} \mathrm{C}$. The samples were placed on a platinum mesh (avoiding contact of the platinum with the polished sample surface) in a quartz holder in well-defined atmosphere conditions (vacuum down to $10^{-8}$ bar, purified Ar gas flow with $p_{\mathrm{O}_{2}}<10^{-24}$ bar, isotope enriched gas mixture or other gas atmospheres).

The experimental work in $\mathrm{O}_{2}$ atmosphere starts with an equilibration of the samples in 0.2 bar ${ }^{16} \mathrm{O}_{2}$ (natural oxygen gas) for at least 10 times the annealing time of the subsequent isotope exchange $\left(t_{\text {eq }}=10 \times t_{\text {ex }}\right)$ in ${ }^{18} \mathrm{O}_{2}$ enriched oxygen gas ( $96 \%$ enrichment) at the same temperature $\left(T_{\text {eq }}=T_{\text {ex }}\right)$. To avoid a change in oxygen partial pressure during the first experimental step the pre-treatment is conducted in steps with renewing gas, and one of the samples is taken as a reference for measuring the actual oxygen isotope background concentration. For the second experimental step, which is the actual oxygen isotope exchange step, the samples are quenched to room temperature, the gas atmosphere is changed from ${ }^{16} \mathrm{O}_{2}$ to ${ }^{18} \mathrm{O}_{2}$ and the oxygen isotope exchange is then conducted at $t_{\mathrm{ex}}$ and $T_{\mathrm{ex}}$. Depending on the expected diffusion length of oxygen in the samples, the analysis is done either with SIMS IEDP or SIMS IELS as described in Figure 10. 

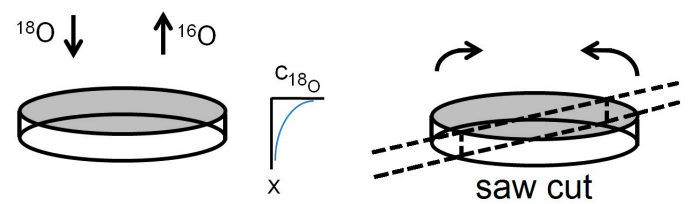

a)

b)

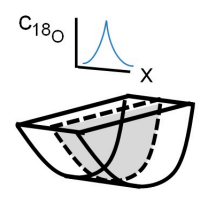

Figure 10. Schematic diagram summarising the SIMS IEDP technique for $\sigma<5 \mu \mathrm{m}$ (a) and the SIMS IELS technique for $10 \mu \mathrm{m}<\sigma<h / 4(\mathbf{b})$. The line scan technique involves sectioning of the sample in a plane perpendicular to the exchange surface and analysing the isotope fraction profile by laterally scanning the primary ion beam across the contact line of the two exposed (half) surfaces.

Differences in sputter yield and ionisation yield can be neglected for isotopes so that the depth distribution of the atomic fraction of ${ }^{18} \mathrm{O}$ isotopes $c\left({ }^{18} \mathrm{O}\right)$ can be quantified via

$$
c\left({ }^{18} \mathrm{O}\right)=\frac{I\left({ }^{18} \mathrm{O}\right)}{I\left({ }^{18} \mathrm{O}\right)+I\left({ }^{16} \mathrm{O}\right)}
$$

from the SIMS raw data, where $I$ is the intensity of the SIMS signal. Figure 11 shows a typical result for a sample which was pre-annealed for $t_{\mathrm{eq}}=5 \mathrm{~h}$ in $0.2 \mathrm{bar}{ }^{16} \mathrm{O}_{2}$ at $T_{\text {eq }}=900{ }^{\circ} \mathrm{C}$ and subsequently annealed for $t_{\mathrm{ex}}=1800 \mathrm{~s}$ in $0.2 \mathrm{bar}{ }^{18} \mathrm{O}_{2}$ at $T_{\mathrm{ex}}=900{ }^{\circ} \mathrm{C}$. The resulting ${ }^{18} \mathrm{O}$ depth profile was analysed by SIMS IELS using TOF-SIMS IV (ION-TOF GmbH, Germany). After cleaning with a Cs ${ }^{+}$ion beam $(2 \mathrm{keV}$, $143 \mathrm{nA})$ the sample was analysed with $\mathrm{Ga}^{+}$ions $(25 \mathrm{keV}, 1.43 \mathrm{nA}$, beam size $1 \mu \mathrm{m})$. Sample charging was prevented by an electron flood gun. Further details are given elsewhere [55]. The background atomic fraction of oxygen isotope was measured separately on a reference sample.
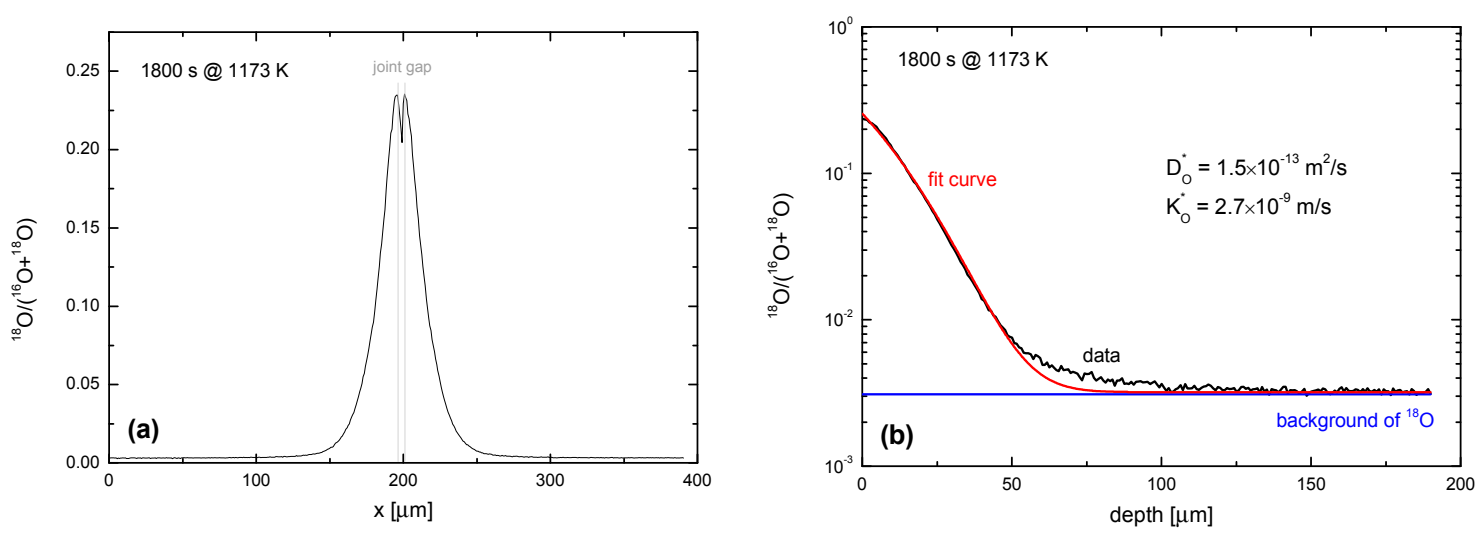

Figure 11. SIMS line scan depth profiles measured in a nominally un-doped polycrystalline ceria sample (with 0.2 at \% La) which was annealed for $t_{\mathrm{ex}}=1800 \mathrm{~s}$ in $0.2 \mathrm{bar}{ }^{18} \mathrm{O}_{2}$ gas at $T_{\mathrm{ex}}=1173 \mathrm{~K}$ in equilibrium conditions. (a) Isotope fraction of ${ }^{18} \mathrm{O}$ perpendicular to the original surface computed by Equation (8); (b) Isotope fraction in comparison with the fit by Equation (7) and the independently measured isotope background.

Oxygen tracer diffusion coefficients in ceria containing either trivalent dopants ( $\mathrm{Gd}, \mathrm{Sm}, \mathrm{Y})$ or a tetravalent dopant $(\mathrm{Zr})$, and of nominally un-doped ceria samples in the temperature range from 700 to $900{ }^{\circ} \mathrm{C}$ from experiments conducted in 0.2 bar $^{18} \mathrm{O}_{2}$ gas atmosphere are shown in Figure 12 together 
with literature data taken from [26]. Calculated activation enthalpies (numerical values in brackets) are also shown in the given temperature range of this work.

Because of the lanthanum impurity in the nominally un-doped ceria samples it is reasonable to assume that the oxygen diffusion in the low temperature region $T<1000{ }^{\circ} \mathrm{C}$ is controlled by this trivalent dopant and therefore extrinsic, as was discussed by Kamiya et al. [26]. A comparison with literature data taken from [26] and references therein as shown in Figure 12 confirms a good agreement of the measured oxygen tracer diffusion coefficients of nominally un-doped ceria in the temperature range $700{ }^{\circ} \mathrm{C}$ to $900{ }^{\circ} \mathrm{C}$ in this work with data taken from [26].

The slope of the curve for nominally un-doped ceria in the Arrhenius plot in Figure 12 is small compared to the slope in the temperature range above $1000{ }^{\circ} \mathrm{C}$, with $T>1000^{\circ} \mathrm{C}$ representing the region of true intrinsic behaviour of un-doped $\mathrm{CeO}_{2}$ [26], and is similar to that of the Sm-doped ceria samples, yielding the same activation enthalpy. In the extrinsic region the experimentally obtained activation enthalpy comprises only the migration enthalpy because of the existence of extrinsic oxygen vacancies introduced by trivalent dopants. The difference in magnitude of the oxygen tracer diffusion coefficients for nominally un-doped ceria and Sm-doped ceria samples in Figure 12 is obviously partially due to the difference in the concentration of the trivalent dopant present on the cation sublattice, being 10 at $\%$ for the yttria-doped ceria samples and about 0.2 at $\%(\mathrm{La})$ for the nominally un-doped ceria samples.

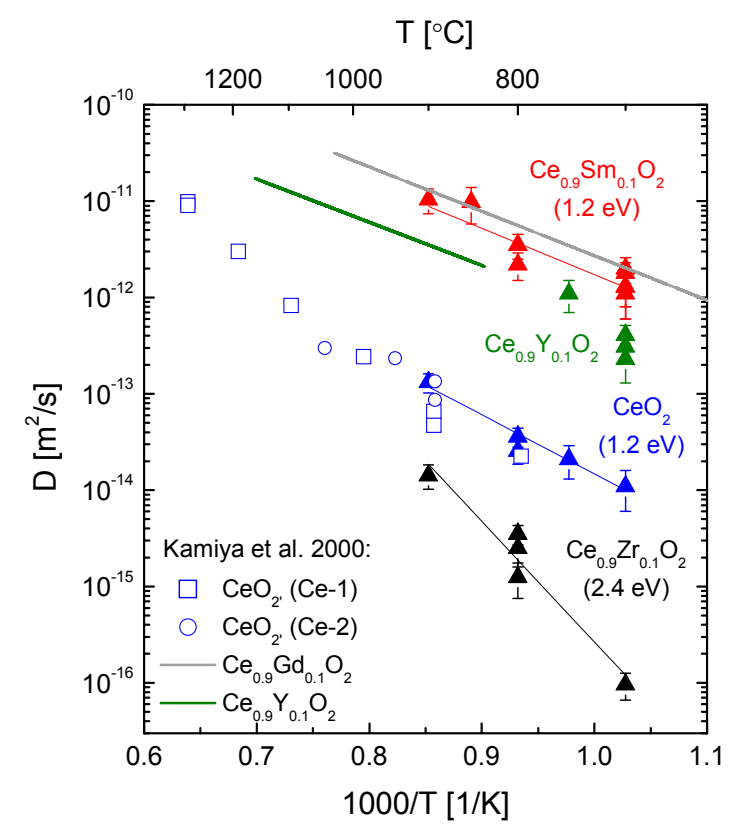

Figure 12. Oxygen tracer diffusion coefficient (this work: data with error bars, numerical values in brackets are corresponding activation enthalpies of oxygen diffusion) in doped and nominally un-doped polycrystalline ceria (with 0.2 at \% La) in the temperature range 973 to $1173 \mathrm{~K}$ compared with literature data taken from Kamiya et al., 2000 [26] and references therein.

\subsection{Oxygen Exchange from $\mathrm{CO}_{2}$ Atmospheres}

The global reaction for $\mathrm{CO}_{2}$ splitting on $\mathrm{CeO}_{2}$ surfaces (confer Equation (2)) is conventionally summarized in Kröger-Vink notation as follows

$$
\mathrm{CO}_{2}+\mathrm{V}_{\mathrm{O}}^{\bullet \bullet}+2 \mathrm{Ce}_{\mathrm{Ce}}^{\prime} \Rightarrow \mathrm{CO}(\mathrm{g})+\mathrm{O}_{\mathrm{O}}^{\times}+2 \mathrm{Ce}_{\mathrm{Ce}}^{\times}
$$

Depending on the experimental conditions, different reaction routes are possible, where the overall reaction path may be divided into different reaction steps. The following reaction scheme 
would be conceivable in accordance with the current ideas on surface exchange from pure oxygen atmosphere [56,57]

$$
\begin{gathered}
\mathrm{CO}_{2}(\mathrm{~g})+\mathrm{S}_{\mathrm{ad}} \Rightarrow \mathrm{CO}_{2}(\mathrm{ad}) \\
\mathrm{CO}_{2}(\mathrm{ad})+\mathrm{e}^{\prime} \Rightarrow \mathrm{CO}_{2}^{\prime}(\mathrm{ad}) \\
\mathrm{CO}_{2}^{\prime}(\mathrm{ad})+\mathrm{e}^{\prime}+\mathrm{S}_{\mathrm{ad}} \Rightarrow \mathrm{CO}(\mathrm{ad})+\mathrm{O}^{\prime \prime}(\mathrm{ad}) \\
\mathrm{CO}(\mathrm{ad})+\mathrm{O}^{\prime \prime}(\mathrm{ad})+\mathrm{V}_{\mathrm{O}}^{\bullet \bullet} \Rightarrow \mathrm{CO}(\mathrm{g})+\mathrm{O}_{\mathrm{O}}^{\times}+2 \mathrm{~S}_{\mathrm{ad}}
\end{gathered}
$$

where $\mathrm{S}_{\mathrm{ad}}$ represents a $\mathrm{CO}_{2}$ adsorption site. Recent investigations revealed a high concentration and a high stability of reactive surface $\mathrm{Ce}^{3+}$ ions over a wide range of temperature and of oxygen partial pressure on ceria surfaces [58], and $\mathrm{Ce}^{3+}$ and oxygen vacancies are generally believed to be the active sites on ceria surfaces and therefore refer to the $S_{\text {ad }}$ adsorption sites [59-61].

It is generally assumed that one of the different reaction steps will be rate determining, with the charge transfer step leading to dissociation being the most likely rate determining step [56,62].

The oxygen partial pressure during experiments using a $\mathrm{CO}_{2}$ gas atmosphere is much lower in comparison to established experimental work using pure oxygen and is determined mainly by the $\mathrm{CO} / \mathrm{CO}_{2}$ ratio of the given gas mixture as shown in Figure 13, by the respective temperature $T$ and/or additional oxygen sources, which should be avoided. Because of the considerable cost of labelled $\mathrm{C}^{18} \mathrm{O}_{2}$ (835 ppm CO, <250 ppm O $\mathrm{O}_{2}$, purchased from Campro Scientific $\mathrm{GmbH}$, Berlin, Germany) a gas mixture with an $\mathrm{Ar} / \mathrm{C}^{18} \mathrm{O}_{2}$ ratio of $10 / 1$ (purified $\mathrm{Ar}, p_{\mathrm{O}_{2}}<10^{-24}$ bar) in a closed volume $(V \approx 1 \mathrm{~L}$ ) was used for the experimental work. The resulting $p_{\mathrm{O}_{2}}$ of the $\mathrm{CO}_{2}$ containing gas mixture was less than $5 \times 10^{-15}$ bar at $T=700^{\circ} \mathrm{C}$. Preconditioning of the samples in terms of oxygen activity was carried out in an $\mathrm{Ar} /{ }^{16} \mathrm{O}_{2}$ mixture with the same oxygen partial pressure as for the isotope exchange experiments.

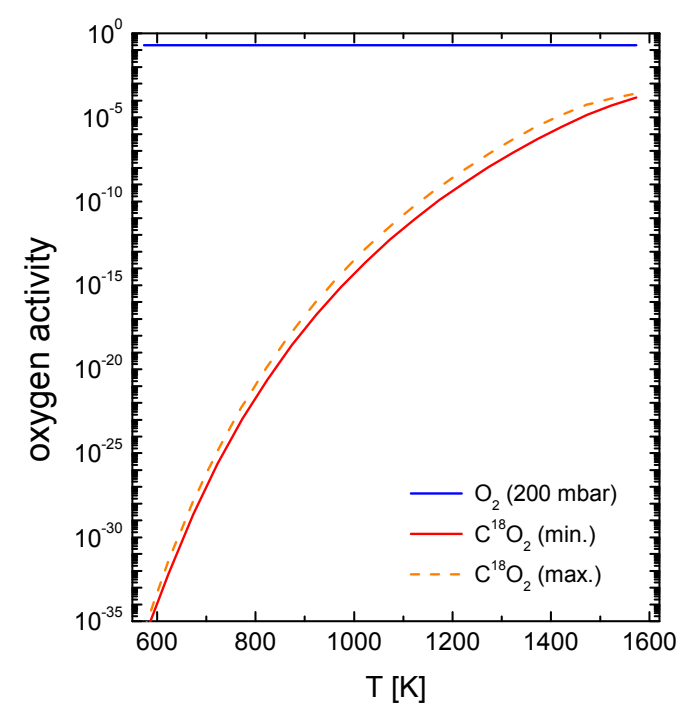

Figure 13. Visualization of the different resulting oxygen activity values utilized in the different $\mathrm{CO}_{2}$ exchange experiments. The oxygen activity for a 0.2 bar oxygen atmosphere and for the $\mathrm{Ar} / \mathrm{C}^{18} \mathrm{O}_{2}$ gas mixture was calculated with Equilib-Web [63] based on the certified gas analysis.

\subsubsection{Measurements with a Chemical Potential Gradient at the Gas/Solid Interface}

Comparable to the low temperature step of the two-step thermochemical cycle for splitting $\mathrm{CO}_{2}$, the experimental work utilizing a chemical potential gradient (difference in the chemical potential of oxygen) at the gas/solid interface starts with reduced (doped or un-doped) ceria samples, with the respective oxygen nonstoichiometry of the sample depending on the temperature of the reduction step and the sample type. The equilibrium oxygen activity of the samples has to be lower than the oxygen activity of the $\mathrm{Ar} / \mathrm{C}^{18} \mathrm{O}_{2}$ gas mixture (as shown in Figure 14) in which the samples are annealed at a given temperature. During the experiment the ${ }^{18} \mathrm{O}$ will be incorporated from $\mathrm{C}^{18} \mathrm{O}_{2}$ into the sample 
bulk, probably following the above mentioned reaction pathway in Equation (10). Because of the closed volume (continuous gas flow is not used due to the limited amount of labelled $\mathrm{C}^{18} \mathrm{O}_{2}$ ) the gradient of the chemical potential of oxygen will change during the experiment for two reasons. First, the oxygen activity in the sample will increase, especially at the sample surface and in the near-surface region of the bulk, due to oxygen incorporation. Second, the oxygen uptake of the samples will decrease the oxygen partial pressure in the gas phase. This is shown in Figure 14 for the reaction of reduced un-doped ceria with an $\mathrm{Ar} / \mathrm{C}^{18} \mathrm{O}_{2}$ gas mixture.

The analytical solution given by Crank [54] in Equation (7) requires constant parameters $D$ and $K$ for the boundary conditions given in Equation (6). It can therefore only be applied if the change in the chemical potential gradient is small and the boundary condition of a constant oxygen concentration at the gas/solid interface is sufficiently fulfilled through choosing carefully the initial oxygen nonstoichiometry of the sample, i.e., initial nonstoichiometry in the flat range of the $p_{\mathrm{O}_{2}}=f(\delta)$ plot. When the ceria sample is initially reduced to $\delta \cong 0.2$, the resulting change in the chemical potential difference of oxygen, $\Delta \mu_{\mathrm{O}_{2}}$, (between the gas phase and the solid) is by a factor of about 3 , and the analytical solution cannot be used with an acceptable error.

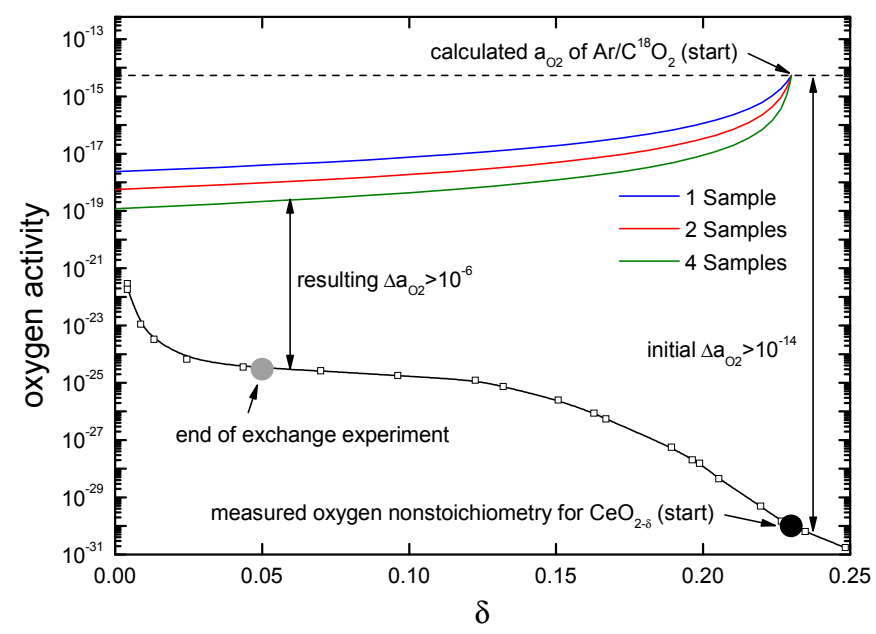

Figure 14. Calculated change in the oxygen activity during the experiment utilizing a chemical potential gradient at the gas/solid interface at $T=700{ }^{\circ} \mathrm{C}$ when the ceria sample is initially reduced up to $\delta>0.2$. Experimental data is taken from reference [64] for reduced un-doped ceria at $T=715{ }^{\circ} \mathrm{C}$. The coloured lines indicate the calculated change of the oxygen activity of the gas atmosphere for 1, 2 or 4 samples used during the oxygen exchange experiment.

\subsubsection{Measurements in Equilibrium}

In contrast to the experiments with a chemical potential gradient of oxygen at the gas/solid interface, $a_{\mathrm{O}_{2}}$ remains constant during the experiment at the given starting value shown in Figure 14 . During the annealing ${ }^{18} \mathrm{O}$ will be incorporated from $\mathrm{C}^{18} \mathrm{O}^{2}$ into the sample bulk, with the exchange of ${ }^{16} \mathrm{O}$ from the sample to the $\mathrm{C}^{18} \mathrm{O}(\mathrm{ad})$ being the backward reaction of the reaction pathway in Equation (10). As was shown by Bueno-López et al. [65], the oxygen exchange mechanism between $\mathrm{C}^{18} \mathrm{O}_{2}$ and ceria samples in equilibrium consists of the exchange of oxygen atoms in two consecutive steps, yielding $\mathrm{C}^{16} \mathrm{O}^{18} \mathrm{O}$ and $\mathrm{C}^{16} \mathrm{O}_{2}$.

The challenge is the preconditioning of the samples to reach real equilibrium. The pre-treatment of the samples was done in a first so-called equilibration step utilizing an $\mathrm{Ar} / \mathrm{CO}_{2}$ gas mixture, realizing equivalent oxygen partial pressures as given in the isotope exchange experiment and plotted in Figure 13. The resulting $p_{\mathrm{O}_{2}}$ was measured in situ with a lambda probe.

Figure 15 shows an ion image $\left({ }^{16} \mathrm{O}\right.$ and ${ }^{18} \mathrm{O}$ in logarithmic scale) of a $10 \%$ yttria-doped ceria sample $\mathrm{Ce}_{0.9} \mathrm{Y}_{0.1} \mathrm{O}_{1.95}$ after an oxygen isotope exchange experiment in an $\mathrm{Ar} / \mathrm{C}^{18} \mathrm{O}_{2}$ gas mixture at 
$973 \mathrm{~K}$ under equilibrium conditions. The sharp line in the middle represents the joint of the juxtaposed original exchange surfaces.

This ion image is used to calculate the ${ }^{18} \mathrm{O}$ concentration along a line perpendicular to the original surface (line scan). The result is shown in Figure 16 together with the fit (analytical solution given in Equation (7)) and the resulting parameters $\left(K_{O}^{*}, D_{O}^{*}\right)$ in the inset. (The asterisk indicates a "tracer" parameter determined at chemical equilibrium between gas phase and oxide surface, i.e., $\Delta \mu_{\mathrm{O}_{2}}=0$. The parameters determined in an experiment with an oxygen potential gradient, i.e., $\Delta \mu_{\mathrm{O}_{2}} \neq 0$, are characterized by a tilde: $\widetilde{K}_{O}, \widetilde{D}_{O}$ ).

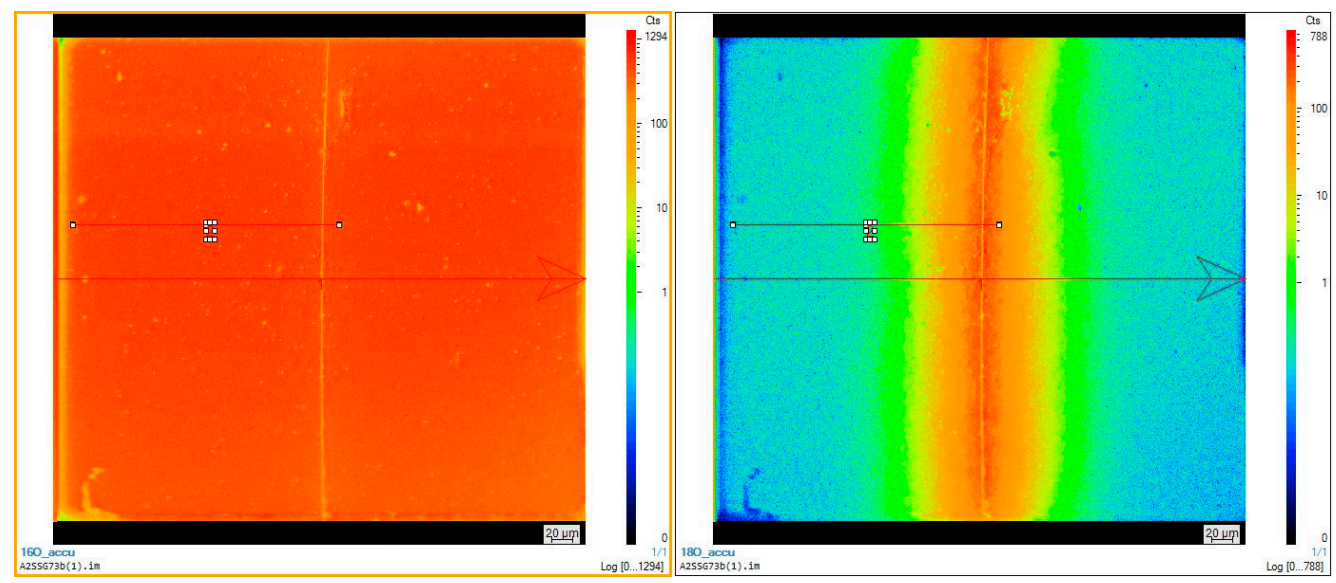

(a)

(b)

Figure 15. Ion image for ${ }^{16} \mathrm{O}(\mathbf{a})$ and ${ }^{18} \mathrm{O}(\mathbf{b})$ (CAMECA 7f, GEMaC, logarithmic scale), $10 \%$ yttria-doped ceria sample $\mathrm{Ce}_{0.9} \mathrm{Y}_{0.1} \mathrm{O}_{1.95}$, oxygen isotope exchange experiment with equilibrium conditions using $\mathrm{Ar} / \mathrm{C}^{18} \mathrm{O}_{2}, \mathrm{~T}=973 \mathrm{~K}$. (Both ion images are screen shots. The blank text boxes are artefacts without physical significance. The arrow indicates the direction of the line scan half of which yielded the data for Figure 16 below.)

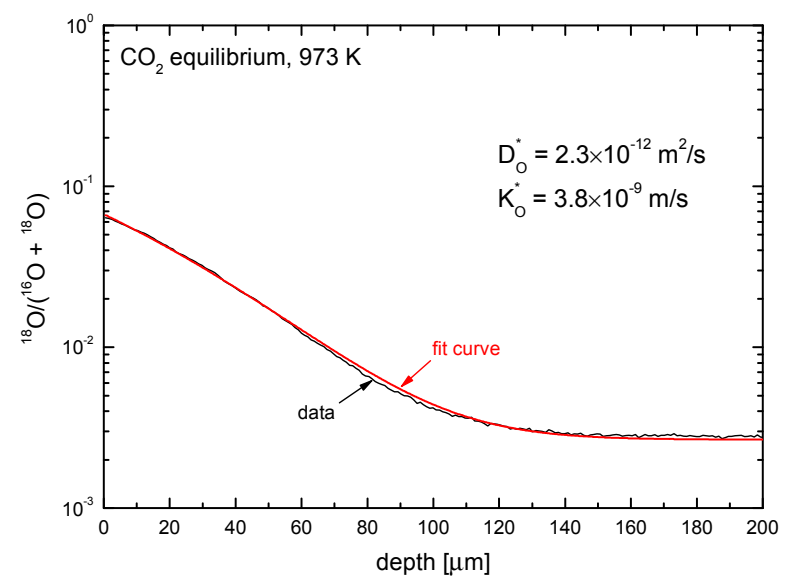

Figure 16. Example for the ${ }^{18} \mathrm{O}$ concentration of a $10 \%$ yttria-doped ceria sample $\mathrm{Ce}_{0.9} \mathrm{Y}_{0.1} \mathrm{O}_{1.95}$ after an oxygen isotope exchange experiment using $\mathrm{Ar} / \mathrm{C}^{18} \mathrm{O}_{2}$ in equilibrium conditions at $T=973 \mathrm{~K}$. Shown are the line scan SIMS measurement and the corresponding parameters $D_{O}^{*}$ and $K_{O}^{*}$.

\subsubsection{Comparison of the Oxygen Exchange Kinetics under Different Conditions}

We measured the kinetic parameters of surface exchange and bulk diffusion of oxygen $\left(\widetilde{K}_{O}, \widetilde{D}_{O}\right.$ and $K_{O}^{*}, D_{O}^{*}$ ) in doped and nominally un-doped ceria samples (with 0.2 at $\% \mathrm{La}$ ) for three different experimental conditions at $T=973 \mathrm{~K}$ (see Table 2). 
Table 2. Experimental parameters related to the experimental condition numbers shown in Figure 17. The oxygen activity during annealing in $\mathrm{C}^{18} \mathrm{O}_{2}$ gas atmosphere is the estimated initial value of the oxygen exchange experiment as shown in Figure 13.

\begin{tabular}{cccc}
\hline Condition Number & Gas Atmosphere & $\boldsymbol{a}_{\boldsymbol{O}_{2}}$ in the Gas Phase & Experimental Condition/ $\boldsymbol{a}_{\boldsymbol{O}_{2}}$ in the Sample Bulk \\
\hline 1 & ${ }^{18} \mathrm{O}_{2}$ & 0.2 & equilibrium $\left(K_{O}^{*}, D_{O}^{*}\right) / 0.2$ \\
2 & $\mathrm{C}^{18} \mathrm{O}_{2}$ & $\approx 10^{-15}$ & equilibrium $\left(K_{O^{\prime}}^{*} D_{O}^{*}\right) / \approx 10^{-15}$ \\
3 & $\mathrm{C}^{18} \mathrm{O}_{2}$ & $\approx 10^{-15} \rightarrow 10^{-19}$ & chem. pot. grad. $\left(\widetilde{K}_{O}, \widetilde{D}_{O}\right) / \approx 10^{-30} \rightarrow 10^{-25}$ \\
\hline
\end{tabular}

The resulting diffusion coefficients $\widetilde{D}_{O}, D_{O}^{*}$ and exchange coefficients $\widetilde{K}_{O}, K_{O}^{*}$ are shown in Figure 17. The overall trends of the diffusion coefficients (as a function of the oxygen activity in the three experimental situations on the one hand and of the nature and the concentration of the different dopants on the other hand) can be, at best, semi-quantitatively rationalized based on the respective total oxygen vacancy concentration (see Figure 17a). With the exception of Zr-doped ceria, a similar trend, though less directly evident, is observed for the exchange coefficient (see Figure 17b).
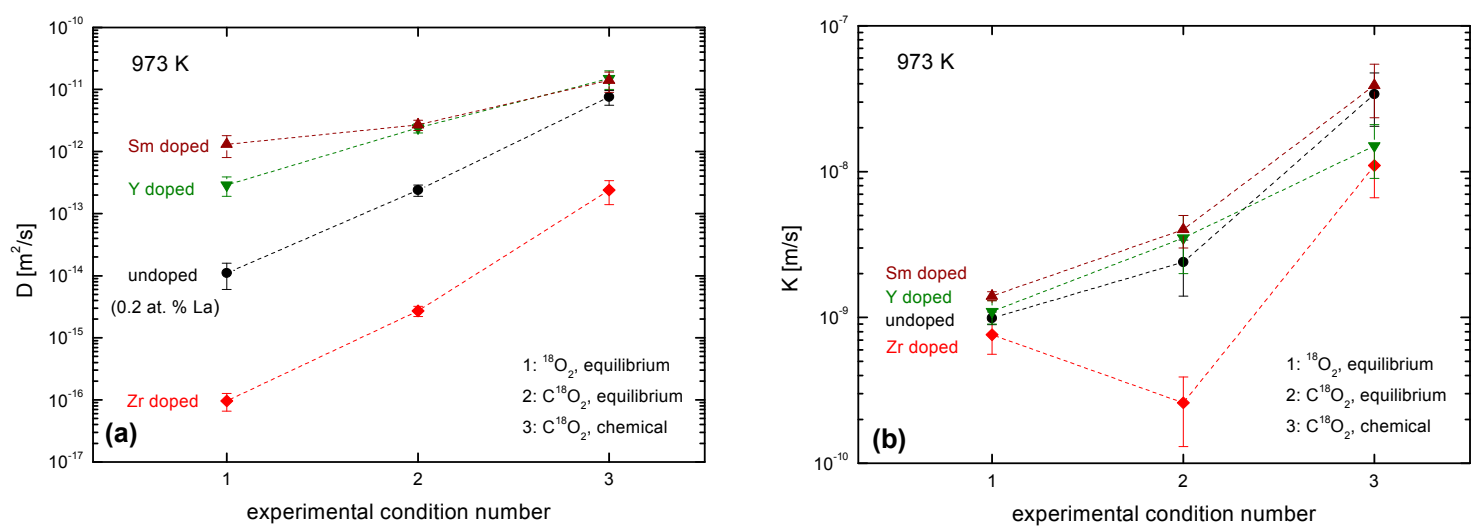

Figure 17. Graphical compilation of (a) measured oxygen diffusion coefficients, $D$; and (b) oxygen surface exchange coefficients, $K$, at $973 \mathrm{~K}$ in nominally un-doped ceria $(0.2$ at $\%$ La) and doped ceria samples (trivalent or tetravalent doping with $10 \% \mathrm{Sm}, \mathrm{Y}, \mathrm{Zr}$ ) under three different experimental conditions (see Table 2). The dashed lines are drawn as a guide for the eye.

As all the discussed isotope exchange experiments were performed in the mixed control regime or in the diffusion control regime (see Figure A2 in Appendix A) the obtained parameters $K$ and $D$ are not independent, which suggests that the alternative approach developed in Appendix A should be employed. Before doing this the reader is referred to the so-called critical length, $D / K$, which is shown in Figure 18a for three different experimental conditions (see Table 2) at $973 \mathrm{~K}$. However, this is only another merely descriptive parameter ratio for technical applications, which is not well suited for more profound interpretation. (The exact role of the platinum support was neither an objective nor could it be quantified in the framework of our investigations. According to recent literature data a ceria surface traps about $1 \mathrm{Pt}$ atom $/ \mathrm{nm}^{2}$ in oxidizing ambient conditions [66]. Anyhow Figure 18b shows in accordance with literature data [65], that, at elevated temperatures, a potential Pt effect is no longer dominant and obviously also depends on the dopant.) 

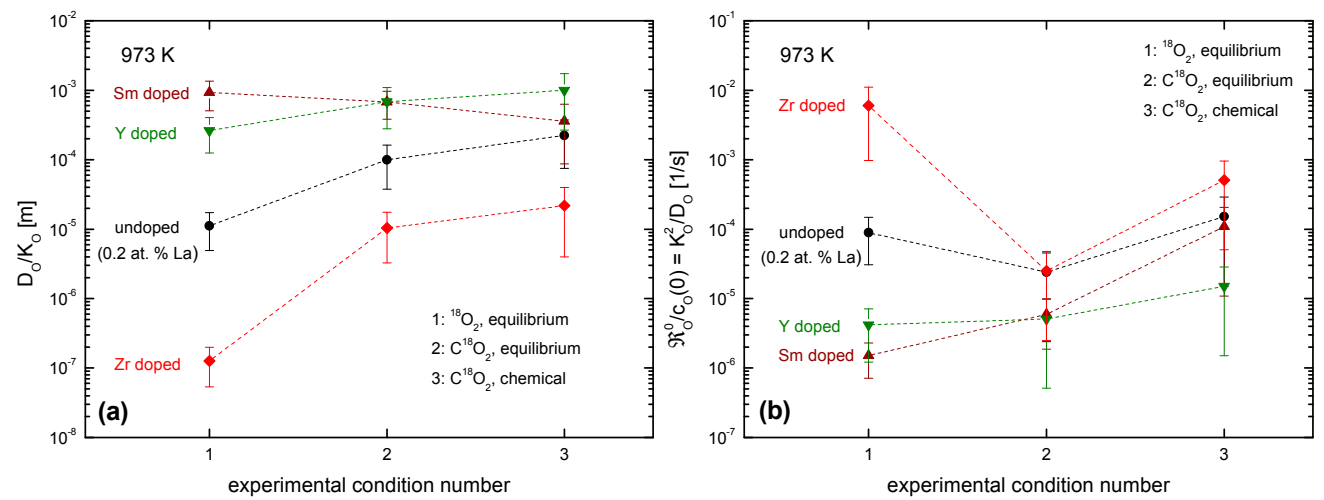

Figure 18. Graphical compilation of derived parameters from measured $K-D$ data: (a) critical length, (b) normalized equilibrium rate constant (see text for the meaning of the derived parameters) for three different experimental conditions (see Table 2) at $973 \mathrm{~K}$. For the evaluation of these derived parameters the $K-D$ data shown in Figure 17 were used.

For a deeper understanding, the normalized equilibrium rate constant $\Re_{O}^{0} / c_{O}(0)$ has to be evaluated via Equation (A4) in Appendix A. For $w_{O}(0) \cong 1$, it reads for "thick" samples $\Re_{O}^{0} / c_{O}(0)=\left(K_{O}^{* h \rightarrow \infty}\right)^{2} / D_{O}^{*}=1 / \tau$. The normalized equilibrium exchange rate constant is thus identical with the reciprocal characteristic time constant to reach (isotope) equilibrium at the surface as discussed above in the context of Equation (7). The resulting plot in Figure 18b reflects obvious dependencies on doping and oxygen activity, which can be qualitatively interpreted with the aid of an expression for $\Re_{O}^{0}$ in the case of charge transfer as the rate determining step in the oxygen incorporation (confer $[34,56]$ ), which reads

$$
\Re_{O}^{0}=\left(\frac{\overleftarrow{k}_{2} \vec{k}_{2} K_{a d}}{K_{\text {inc }}}\right)^{1 / 2}\left(c_{O} c_{e} c_{h}\right)^{1 / 2} \frac{a_{\mathrm{O}_{2}}^{1 / 4}}{c_{v}^{1 / 2}} \cong \text { const. } \times \frac{a_{\mathrm{O}_{2}}^{1 / 4}}{c_{v}^{1 / 2}}
$$

(Regarding the different quantities in the master Equation (11) the reader is referred to Equation (A6) in Appendix A.) For the experimental condition \#1 $\left(a_{\mathrm{O}_{2}}=0.2\right.$ both in the gas phase and in the solid) $\Re_{O}^{0}$ decreases with increasing concentration of the trivalent dopant while $\mathrm{Zr}$ seems to neutralize the La contamination. For the experimental condition $\# 2\left(a_{\mathrm{O}_{2}} \cong 10^{-15}\right.$ both in the gas phase and in the solid) $c_{v}$ increases strongly for the $\mathrm{Zr}$ doped material, but less for the trivalent-doped material and thus causes a strong decrease in $\Re_{O}^{0}$ for the $\mathrm{Zr}$-doped material, and no big change for the trivalent-doped material. For the experimental conditions \#3 the discussion is less straightforward. Here the solid is equilibrated to $a_{\mathrm{O}_{2}}=10^{-25}$ while the gas phase has a (starting) oxygen activity $a_{\mathrm{O}_{2}}=10^{-15}$. For the time being more experimental information is needed and an interpretation on the basis of Equation (11) would be premature.

\section{Conclusions}

Redox studies on zirconia-doped ceria revealed selective sublimation of ceria from ceria-zirconia solid solutions when reduction temperatures are above $1600 \mathrm{~K}$ and gas pressures were low. As a consequence surface segregation of zirconia occurs in $(\mathrm{Ce}, \mathrm{Zr}) \mathrm{O}_{2-\delta}$ pellets and a porous surface zone of $\mathrm{Ce}_{2} \mathrm{Zr}_{2} \mathrm{O}_{7}$ pyrochlore is observed which gradually grows in thickness. Surface enrichment of zirconia is detrimental for splitting $\mathrm{CO}_{2}$ or $\mathrm{H}_{2} \mathrm{O}$ since re-oxidation temperatures of $(\mathrm{Ce}, \mathrm{Zr}) \mathrm{O}_{2-\delta}$ are known to be shifted towards lower temperatures with increasing $\mathrm{ZrO}_{2}$ content. Thus, very harsh reduction conditions should be avoided for the $(\mathrm{Ce}, \mathrm{Zr}) \mathrm{O}_{2-\delta}$ redox system.

The kinetics investigations focus on the oxygen exchange and diffusion during the high temperature reduction steps $(T \approx 1600 \mathrm{~K})$ and on the respective kinetics of the "low" temperature 
( $T \cong 1000 \mathrm{~K}$ ) oxidation reaction with a carbon dioxide atmosphere. Based on a recent extension of the current phenomenological treatment of the exchange kinetics by the present authors, the thermogravimetric analyses of the reduction kinetics (at around $1600 \mathrm{~K}$ and an oxygen activity of $7 \times 10^{-4}$ in the gas phase) directly yield the (reduction) equilibrium exchange rate of oxygen in the order of $10^{-7} \mathrm{~mol} \cdot \mathrm{O} /\left(\mathrm{cm}^{3} \cdot \mathrm{s}\right)$ as the kinetics are surface controlled. The oxidation step at around $1000 \mathrm{~K}$, however, occurs in the mixed control or in the diffusion control regime, respectively. Here, oxygen isotope exchange in combination with SIMS depth profiling is the method of choice for pure oxygen atmosphere and carbon dioxide atmosphere, both labelled with ${ }^{18} \mathrm{O}$. With this tracer technique oxygen exchange coefficients, $K$, and oxygen diffusivities, $D$, were determined for so-called equilibrium experiments $\left(\mu_{\mathrm{O}_{2}}\right.$ (solid) $=\mu_{\mathrm{O}_{2}}$ (gas) ) as well as for non-equilibrium measurements $\left(\mu_{\mathrm{O}_{2}}\right.$ (solid) $\neq \mu_{\mathrm{O}_{2}}$ (gas)). From the experimentally observed values for $K$ and $D$ the (oxidation) equilibrium exchange rates for differently doped ceria samples were determined. Their dependency on the oxygen activity and the nature and the concentrations of a tetravalent dopant $(\mathrm{Zr})$ and trivalent dopants ( $\mathrm{La}, \mathrm{Y}, \mathrm{Sm}$ ) can be semi-quantitatively rationalised on the basis of a master equation for the equilibrium surface exchange rate. (In our study, the potential role of Pt traces on the numerical value of the oxygen exchange rate could not be addressed. It seems that this is implicitly true for most of the published studies on oxygen surface exchange kinetics at high temperatures. But the influence of platinum seems to decrease with increasing temperatures [65] and the exchange rate then mostly depends on the very nature of the surface, i.e., on the dopants.)

Acknowledgments: Financial support by the Initiative and Networking Fund of the Helmholtz Association of German Research Centers within the Virtual Institute SolarSynGas as well as by Deutsche Forschungsgemeinschaft (DFG) for one of the authors (P.F.) is gratefully acknowledged. Thanks to the Schöne Familienstiftung a PhD student (D.U.) could be partially funded. We are indebted to M. Schulz, F. Jomard and C. Argirusis for some SIMS line scans and to S. Fischer for technical assistance with the sample preparation. R. Pitz-Paal and M. Roeb very efficiently steered the research work of the Virtual Institute. Constructive criticism of anonymous reviewers helped to improve the manuscript.

Author Contributions: Nicole Knoblauch: sample preparation, thermogravimetric and dilatometric studies; Heike Simon: TEM investigations; Lars Dörrer: design and construction of the oxygen isotope exchange apparatus, SIMS-IEDP analyses; Daniel Uxa: performance of the oxygen exchange experiments in ${ }^{18} \mathrm{O}_{2}$ and $\mathrm{C}^{18} \mathrm{O}_{2}$ atmospheres; Stefan Beschnitt: performance of SIMS line scans; Peter Fielitz: kinetics data evaluation and interpretation, text assembling; Jens Wendelstorf: thermodynamic calculations; Karl-Heinz Spitzer: computer simulations of kinetic parameters; Martin Schmücker: SEM investigations, data interpretation, text composition; Günter Borchardt: physico-chemical discussion of the results, text composition.

Conflicts of Interest: The authors declare no conflict of interest.

\section{Appendix A}

A major reason for the conventional assumption that the oxygen exchange coefficient $K_{O}$ and the oxygen diffusivity $D_{O}$ are independent parameters can be identified in the methodology of standard oxygen exchange experiments [52]: Here the oxygen flux $j_{O}^{K}$ through a surface element subject to an oxygen concentration difference $\Delta c_{O}$ is expressed as follows

$$
j_{O}^{K}(0)=-K_{O} \Delta c_{O}(0)
$$

The phenomenological Equation (A1) defines $K_{O}$ without recurring to any microscopic mechanism.

Figure A1 schematically represents a gas/oxide interface of a homogeneous semi-infinite solid oxide. $D$ is the self-diffusion coefficient of oxygen ions $\left(D_{O}\right)$ in the solid oxide, $p$ is the oxygen partial pressure $\left(p_{\mathrm{O}_{2}}\right)$ in the gas phase and $R$ is the equilibrium oxygen exchange rate $\left(\Re_{O}^{0}\right)$ at the interface. At $t=0$ a small step-like change $\delta \mu(0)$ of the chemical potential of oxygen $\left(\delta \mu_{O}(x=0)\right)$ is experimentally induced at the gas/oxide interface at $x=0$. As Equation (A1) is only valid for surface reactions at $x=0$ it seemed plausible that $K_{O}$ depends exclusively on the defect chemistry of the surface. As we will see below, this assumption is not generally correct either. 
In 1998 Maier [32] proposed a relation between $K_{O}$ and the equilibrium oxygen exchange rate $\Re_{O}^{0}$ at the gas/solid interface (see Maier [32], page 222, Equation (149))

$$
\frac{K_{O}}{\Delta x}=\frac{\Re_{O}^{0}}{c_{O}(0)} w_{O}(0) \quad \text { with }\left.\quad w_{O}(0) \equiv \frac{c_{O}(0)}{R T} \frac{\partial \mu_{O}}{\partial c_{O}}\right|_{x=0}
$$

where $c_{O}(0)$ is the oxygen equilibrium concentration near the surface, $w_{O}(0)$ is the thermodynamic factor near the surface, $R$ and $T$ have the usual meaning, and $\mu_{O}$ is the chemical potential of oxygen. $\Re_{O}^{0}$ is the equilibrium oxygen exchange rate of the rate determining step in a consecutive reaction sequence [56,67]. The quantitative measure of the parameter $\Delta x$ (with the dimension of a length) having been left undefined, Maier's suggestion essentially means that $K_{O}$ is proportional to $\Re_{O}^{0}$ [68].

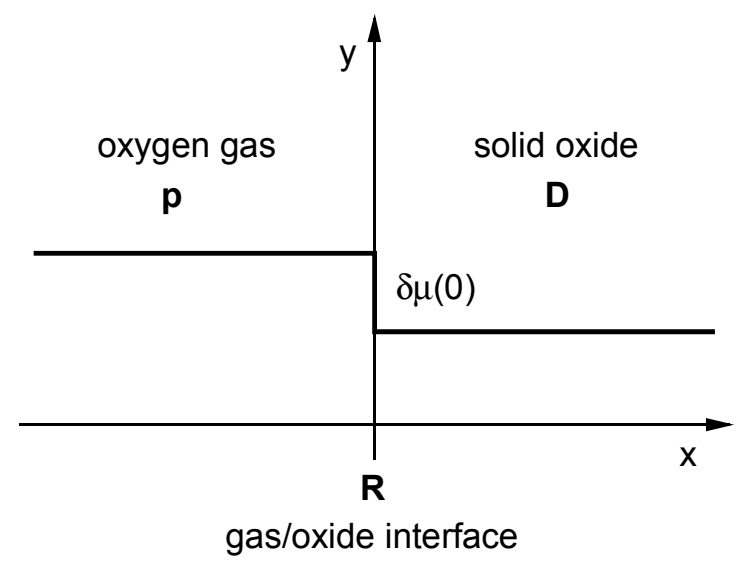

Figure A1. Schematic representation of a gas/oxide interface of a homogeneous semi-infinite solid oxide (see text for the meaning of the symbols).

The relation between the oxygen exchange coefficient in an equilibrium experiment, $K_{O}^{*}$, and in the corresponding non-equilibrium exchange experiment, $\widetilde{K}_{O}$, reads $\widetilde{K}_{O}=w_{O}(0) K_{O}^{*}$. From $\widetilde{D}_{O}=w_{O}(0) D_{O}=w_{O}(0) D_{O}^{*} / f_{O}$, where $D_{O}$ is the self-diffusion coefficient and $D_{O}^{*}$ is the tracer diffusion coefficient of oxygen, respectively, follows with the correlation factor $f_{O} \approx 1$ a simple relation [68]. From $\widetilde{D}_{O}=w_{O}(0) D_{O}=w_{O}(0) D_{O}^{*} / f_{O}$, where $D_{O}$ is the self-diffusion coefficient and $D_{O}^{*}$ is the tracer diffusion coefficient of oxygen, respectively, follows with the correlation factor $f_{O} \approx 1 \mathrm{a}$ simple relation [68]

$$
\frac{K_{O}^{*}}{D_{O}^{*}} \cong \frac{\widetilde{K}_{O}}{\widetilde{D}_{O}}
$$

Throughout the text an asterisk characterizes a parameter determined in an isotope exchange experiment, whereas a tilde refers to a parameter determined in a chemical exchange experiment. Whenever this distinction is irrelevant on theoretical grounds the specification is omitted.

In 2006 De Souza [56] explicitly pointed out that there is a generally observed discrepancy between experimentally determined $K_{O} / D_{O}$ ratios and the theoretically expected ratios according to Equation (A3). Instead of fulfilling Equation (A3) the experimental data yield $K_{O}^{*} / D_{O}^{*}>\widetilde{K}_{O} / \widetilde{D}_{O}$. This was a first significant experimental indication that the consequences resulting from Equation (A2) might not fully cover all aspects of the problem.

Armstrong et al. [29,69] used in 2011 and 2013 a novel experimental approach, called isothermal isotope exchange (IIE), to extract accurate $K_{O}^{*}$ values in a surface exchange controlled regime. Very unexpectedly Armstrong et al. $[29,69]$ found apparent activation energies of $K_{O}^{*}$ with negative (!) or very small positive values for different lanthanum based MIEC perovskite oxides, but also for the standard oxygen ion conductors YSZ and GDC, which have fluorite structure. The reported range of apparent activation energies of the oxygen tracer surface exchange coefficient is $-97 \mathrm{~kJ} / \mathrm{mol}$ 
to $+12 \mathrm{~kJ} / \mathrm{mol}$ and is in strong contrast to the reported range from $+60 \mathrm{~kJ} / \mathrm{mol}$ to $+333 \mathrm{~kJ} / \mathrm{mol}$ measured by conventional methods generally using macroscopic sample geometries, i.e., IEDP/SIMS and electrical conductivity relaxation (ECR) (see Table 5 in Armstrong et al. [69]). These experimental results suggest that the measured oxygen surface exchange coefficient $K_{O}$, if measured in the mixed controlled regime and in the diffusion controlled regime, may depend not only on the equilibrium oxygen exchange rate $\Re_{O}^{0}$ at the gas/solid interface but also on the oxygen diffusion coefficient $D_{O}$ in the bulk. Such a behaviour would clearly contradict Equation (A2) which postulates that $K_{O}$ depends on $\Re_{O}^{0}$ only in all kinetic regimes.

In our earlier joint work on nominally un-doped ceria [33] we also observed a vanishing apparent activation energy of the chemical oxygen surface exchange coefficient $\widetilde{K}_{O}$ in the surface exchange controlled regime.

Summarising one has the following experimental contradictions to the consequences of Equations (A2) and (A3):

(a) Kilner's correlation [46]: $K_{O} \propto D_{O}^{1 / 2}$

(b) De Souza's conclusion [56]: $K_{O}^{*} / D_{O}^{*}>\widetilde{K}_{O} / \widetilde{D}_{O}$

(c) Armstrong et al. [29,69] (for $K_{O}^{*}$ ) and Knoblauch et al. [33] (for $\widetilde{K}_{O}$ ) found very low values for the activation energy of the surface exchange coefficient in the true surface exchange controlled regime.

For the necessary revision of the existing theoretical approach according to Maier et al. $[32,68]$ we expanded Maier's treatment and included diffusional transport in the bulk. Thus coupling surface exchange to subsequent transport in the bulk we could recently [34] explain the discrepancies (a) through (c).

For (a) and (c): If the TGR samples are sufficiently thick (thickness $h \rightarrow \infty$ ) the diffusion controlled regime with $L>30$ (see Figure A2) is valid. As shown in detail in [34] the exchange coefficient becomes

$$
K_{O}^{h \rightarrow \infty}=\left(w_{O}(0) \cdot D_{O} \cdot \Re_{O}^{0} / c_{O}(0)\right)^{1 / 2} \propto D_{O}^{1 / 2}
$$

This means that Kilner's data compilation [46] comprises only experiments performed in the diffusion controlled regime. The authors' conclusion that their empirical correlation for the activation enthalpies $\Delta H_{K}$ (for $K_{O}$ ) and $\Delta H_{D}$ (for $D_{O}$ ), which is $\Delta H_{K} \approx 0.5 \Delta H_{D}$ [46], has a sound physical basis, would be only true if $w_{O}(0)$ and $c_{O}(0)$, but especially $\Re_{O}^{0}$, were no material specific parameters and if all three of them would not depend on temperature at all-which is not the case. According to Equation (A4) the activation energy of $K_{O}^{h \rightarrow \infty}$ is, however, the mean value of the individual activation energies of $D_{O}(T)$ and $\Re_{O}^{0}(T)$. 


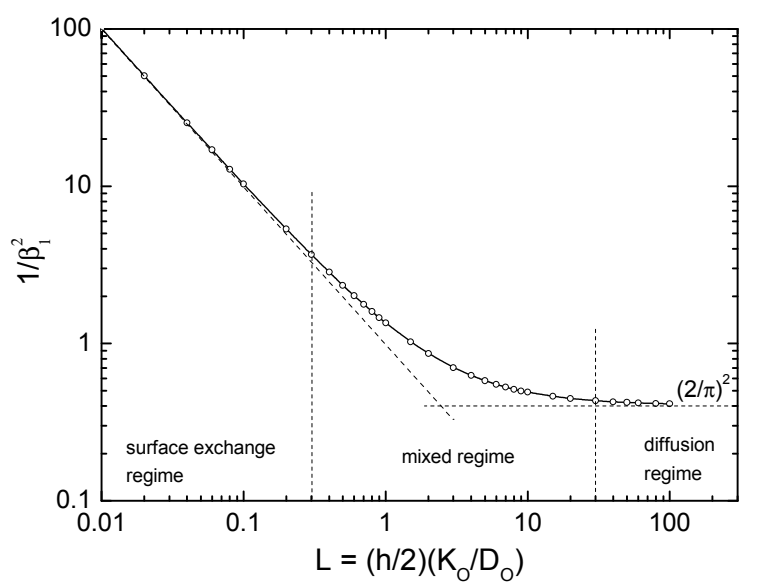

Figure A2. Graphical visualisation of the kinetic regimens [33] (open points are positive roots of $\beta_{1} \tan \beta_{1}=L$ tabulated by Carslaw and Jaeger [70]). The diffusion controlled regime is characterised by $\beta_{1}^{2} \approx \pi^{2} / 4$ and the surface exchange controlled regime by $\beta_{1}^{2} \approx L$.

In the true surface exchange controlled regime $(h \rightarrow 0)$ one gets for sufficiently thin samples [34]

$$
K_{O}^{h \rightarrow 0}=\frac{h}{2} \frac{w_{O}(0)}{c_{O}(0)} \Re_{O}^{0}
$$

In this case the activation energy is presumably much smaller. Because of the complex structure of the equilibrium exchange rate [34]

$$
\Re_{O}^{0}=\left(\frac{\vec{k}_{r d s} \overleftarrow{k}_{r d s} K_{a d}}{K_{i n c}}\right)^{1 / 2} \cdot F\left(c_{O}, c_{e}, c_{h}, c_{v}, a_{O_{2}}\right)
$$

it could be very small or even formally negative within the usual error range of experimental activation energy values. Here $\vec{k}_{r d s}$ and $\overleftarrow{k}_{r d s}$ are the rate constants of the forward and of the backward reaction, respectively, of the rate determining step (rds), $K_{a d}$ and $K_{i n c}$ are the mass law constants of the (oxygen) adsorption and of the (oxygen) incorporation step, respectively; $c_{O}, c_{e}, c_{h}, c_{v}$ stand for the oxygen concentration, the electron and the defect electron concentration and for the oxygen vacancy concentration, respectively.

For (b): In [34] we derive a generally valid relation between the tracer parameters $\left(K_{O}^{*}, D_{O}^{*}\right)$ and the chemical parameters $\left(\widetilde{K}_{O}, \widetilde{D}_{O}\right)$ :

$$
\frac{K_{O}^{*}}{D_{O}^{*}}=\left(\frac{w_{O}(0)}{f_{O}}\right)^{1 / 2} \frac{\widetilde{K}_{O}}{\widetilde{D}_{O}} \text { with }\left(\frac{w_{O}(0)}{f_{O}}\right)^{1 / 2}>1
$$

(Here $f_{O} \approx 1$ is the structural correlation factor). As for oxides $w_{O}(0)>1$ the reason for the discrepancy between Maier's result [32] and De Souza's conclusion [56] becomes evident: Instead of Equation (A3), Equation (A7) has to be used.

In a TGR experiment performed in the surface controlled regime the experimentally accessible time constant $\tau$ is

$$
\tau=\frac{h}{2} \widetilde{K}_{O}^{-1}=\frac{c_{O}(0)}{w_{O}(0)}\left(\Re_{O}^{0}\right)^{-1}
$$

With $\widetilde{K}_{O}$ from Equation (A5), $\tau$ no longer depends on the sample thickness $h$, and the equilibrium exchange rate becomes

$$
\Re_{O}^{0}=\frac{c_{O}(0)}{w_{O}(0)} \cdot \frac{1}{\tau}
$$




\section{Appendix B}

One direct way to follow the kinetics of oxygen uptake or release in situ at high temperatures is a gravimetric experiment [33]. For plate-like samples with thickness $h$ and with both large faces in contact with the atmosphere the mass change, $\Delta m(t)$, if normalized to the mass change at equilibrium, $\Delta m\left(t_{e q}\right)$, is given by Crank [54] (page 60)

$$
\frac{\Delta m(t)}{\Delta m\left(t_{e q}\right)}=1-\sum_{n=1}^{\infty} \frac{2 L^{2}}{\beta_{n}^{2}\left(\beta_{n}^{2}+L^{2}+L\right)} \exp \left(-\beta_{n}^{2} \frac{D_{O} t}{(h / 2)^{2}}\right) \quad \text { with } \quad L \equiv \frac{h}{2} \frac{K_{O}}{D_{O}}
$$

The dimensionless quantities $\beta_{n}$ are positive roots of $\beta_{n} \tan \beta_{n}=L$. As the infinite sum in Equation (B1) converges rapidly one gets approximately [33]

$$
\frac{\Delta m(t)}{\Delta m\left(t_{e q}\right)} \approx 1-\frac{2 L^{2}}{\beta_{1}^{2}\left(\beta_{1}^{2}+L^{2}+L\right)} \exp \left(-\beta_{1}^{2} \frac{D_{O} t}{(h / 2)^{2}}\right)=1-\phi\left(\beta_{1}, L\right) \exp \left(-\beta_{1}^{2} \frac{D_{O} t}{(h / 2)^{2}}\right)
$$

where, strictly speaking, $D_{O}=\widetilde{D}_{O}$ is the chemical diffusion coefficient of oxygen in the solid and $K_{O}=\widetilde{K}_{O}$ is the corresponding surface exchange coefficient of oxygen defined by Equation (A1) in Appendix A. Both parameters are assumed constant in the experimental $\Delta m(t)$ range, which means that the difference in the chemical potential of oxygen, $\Delta \mu_{O}$, between the $\mathrm{O}_{2}$ gas atmosphere and the oxide sample should be tolerably "small" (which, however, depends on the defect thermodynamics of the mass transport in the bulk).

The relevant positive roots of $\beta_{1} \tan \beta_{1}=L$ are plotted in Figure A2 which allows a graphical visualisation of the kinetic regimes. The values of the resulting dimensionless parameters of the kinetic regimes are compiled in Table B1.

Table B1. Characteristic parameters of the kinetic regimes.

\begin{tabular}{cccccc}
\hline Kinetic Regime & $L=(\boldsymbol{h} / \mathbf{2})\left(K_{\boldsymbol{O}} / \boldsymbol{D}_{\boldsymbol{O}}\right)$ & $\boldsymbol{\phi}\left(\boldsymbol{\beta}_{\mathbf{1}}, \boldsymbol{L}\right)$ & $\boldsymbol{\beta}_{1}^{2}$ & $\boldsymbol{D}_{\boldsymbol{O}}$ & $\boldsymbol{\tau}$ \\
\hline Surface Controlled & $<0.3$ & 1 & $L$ & $>3\left(\frac{h}{2} K_{O}\right)$ & $\frac{h}{2} \frac{1}{K_{O}}$ \\
Mixed Regime & 0.3 to 30 & $\cdots$ & $\cdots$ & $\cdots$ & $\cdots$ \\
Diffusion Regime & $>30$ & $8 / \pi^{2}$ & $\pi^{2} / 4$ & $<\frac{1}{30}\left(\frac{h}{2} K_{O}\right)$ & $\frac{4}{\pi^{2}}\left(\frac{h}{2}\right)^{2} \frac{1}{D_{O}}$ \\
\hline
\end{tabular}

If possible, any TGR experiment should be run either unambiguously in the surface controlled regime $(L<0.3)$ or clearly in the diffusion controlled regime $(L>30)$ in order to enable a sound theoretical interpretation of the obtained values of $\tau$. For experiments carried on in a mixed controlled regime $(0.3<L<30)$ the interpretation is less easy as it requires more theoretical information as described in Appendix A.

\section{References}

1. Abanades, S.; Flamant, G. Thermochemical hydrogen production from a two-step solar-driven water-splitting cycle based on cerium oxides. Sol. Energy 2006, 80, 1611-1623. [CrossRef]

2. Ackermann, S.; Scheffe, J.R.; Steinfeld, A. Diffusion of Oxygen in Ceria at Elevated Temperatures and Its Application to $\mathrm{H}_{2} \mathrm{O} / \mathrm{CO}_{2}$ Splitting. J. Phys. Chem. C 2014, 118, 5216-5225. [CrossRef]

3. Bulfin, B.; Lowe, A.J.; Keogh, K.A.; Murphy, B.E.; Lübben, O.; Krasnikov, S.A.; Shvets, I.V. Analytical Model of $\mathrm{CeO}_{2}$ Oxidation and Reduction. J. Phys. Chem. C 2013, 117, 24129-24137. [CrossRef]

4. Chueh, W.C.; Haile, S.M. A thermochemical study of ceria: Exploiting an old material for new modes of energy conversion and $\mathrm{CO}_{2}$ mitigation. Philos. Trans. R. Soc. A Math. Phys. Eng. Sci. 2010, 368, 3269-3294. [CrossRef] [PubMed]

5. Zhou, G.; Shah, P.R.; Montini, T.; Fornasiero, P.; Gorte, R.J. Oxidation enthalpies for reduction of ceria surfaces. Surf. Sci. 2007, 601, 2512-2519. [CrossRef] 
6. Shah, P.R.; Kim, T.; Zhou, G.; Fornasiero, P.; Gorte, R.J. Evidence for Entropy Effects in the Reduction of Ceria-Zirconia Solutions. Chem. Mater. 2006, 18, 5363-5369. [CrossRef]

7. Zhou, G.; Shah, P.R.; Kim, T.; Fornasiero, P.; Gorte, R.J. Oxidation entropies and enthalpies of ceria-zirconia solid solutions. Catal. Today 2007, 123, 86-93. [CrossRef]

8. Kim, T.; Vohs, J.M.; Gorte, R.J. Thermodynamic Investigation of the Redox Properties of Ceria-Zirconia Solid Solutions. Ind. Eng. Chem. Res. 2006, 45, 5561-5565. [CrossRef]

9. Bulfin, B.; Hoffmann, L.; Oliveira, L.; Knoblauch, N.; Call, F.; Roeb, M.; Sattler, C.; Schmücker, M. Statistical thermodynamics of non-stoichiometric ceria and ceria zirconia solid solutions. Phys. Chem. Chem. Phys. 2016, 18, 23147-23154. [CrossRef] [PubMed]

10. Kuhn, M.; Bishop, S.R.; Rupp, J.L.M.; Tuller, H.L. Structural characterization and oxygen nonstoichiometry of ceria-zirconia $\left(\mathrm{Ce}_{1-x} \mathrm{Zr}_{x} \mathrm{O}_{2-\delta}\right)$ solid solutions. Acta Mater. 2013, 61, 4277-4288. [CrossRef]

11. Hao, Y.; Yang, C.-K.; Haile, S.M. Ceria-Zirconia Solid Solutions $\left(\mathrm{Ce}_{1-x} \mathrm{Zr}_{x} \mathrm{O}_{2-\delta}, x \leq 0.2\right)$ for Solar Thermochemical Water Splitting: A Thermodynamic Study. Chem. Mater. 2014, 26, 6073-6082. [CrossRef]

12. Takacs, M.; Scheffe, J.R.; Steinfeld, A. Oxygen nonstoichiometry and thermodynamic characterization of $\mathrm{Zr}$ doped ceria in the 1573-1773 K temperature range. Phys. Chem. Chem. Phys. 2015, 17, 7813-7822. [CrossRef] [PubMed]

13. Huang, S.; Li, L.; Van der Biest, O.; Vleugels, J. Influence of the oxygen partial pressure on the reduction of $\mathrm{CeO}_{2}$ and $\mathrm{CeO}_{2}-\mathrm{ZrO}_{2}$ ceramics. Solid State Sci. 2005, 7, 539-544. [CrossRef]

14. Huang, S.; Li, L.; Vleugels, J.; Wang, P.; Van der Biest, O. Thermodynamic prediction of the nonstoichiometric phase $\mathrm{Zr}_{1-z} \mathrm{Ce}_{z} \mathrm{O}_{2-x}$ in the $\mathrm{ZrO}_{2}-\mathrm{CeO}_{1.5}-\mathrm{CeO}_{2}$ system. J. Eur. Ceram. Soc. 2003, 23, 99-106. [CrossRef]

15. Sanjuan, M.L.; Oliete, P.B.; Varez, A.; Sanz, J. The role of Ce reduction in the segregation of metastable phases in the $\mathrm{ZrO}_{2}-\mathrm{CeO}_{2}$ system. J. Eur. Ceram. Soc. 2012, 32, 689-696. [CrossRef]

16. Montini, T.; Banares, M.A.; Hickey, N.; Di Monte, R.; Fornasiero, P.; Kaspar, J.; Graziani, M. Promotion of reduction in $\mathrm{Ce}_{0.5} \mathrm{Zr}_{0.5} \mathrm{O}_{2}$ : The pyrochlore structure as effect rather than cause? Phys. Chem. Chem. Phys. 2004, 6, 1-3. [CrossRef]

17. Achary, N.S.; Sali, S.K.; Kulkarni, N.K.; Krishna, P.S.R.; Shinde, A.B.; Tyagi, A.K. Intercalation/Deintercalation of Oxygen: A Sequential Evolution of Phases in $\mathrm{Ce}_{2} \mathrm{O}_{3} / \mathrm{CeO}_{2}-\mathrm{ZrO}_{2}$ Pyrochlores. Chem. Mater. 2009, 21, 5848-5859. [CrossRef]

18. Conesa, J.C. Computer Modeling of Local Level Structures in (Ce, Zr) Mixed Oxide. J. Phys. Chem. B 2003, 107, 8840-8853. [CrossRef]

19. Wang, H.-F.; Guo, Y.-L.; Lu, G.-Z.; Hu, P. Maximizing the Localized Relaxation: The Origin of the Outstanding Oxygen Storage Capacity of $\mathrm{k}-\mathrm{Ce}_{2} \mathrm{Zr}_{2} \mathrm{O}_{8}$. Angew. Chem. Int. Ed. 2009, 48, 8289-8292. [CrossRef] [PubMed]

20. Montini, T.; Hickey, N.; Fornasiero, P.; Graziani, M.; Bañares, M.A.; Martinez-Huerta, M.; Alessandri, I.; Depero, L.E. Variations in the Extent of Pyrochlore-Type Cation Ordering in $\mathrm{Ce}_{2} \mathrm{Zr}_{2} \mathrm{O}_{8}: \mathrm{At}^{\prime}-\kappa$ Pathway to Low-Temperature Reduction. Chem. Mater. 2005, 17, 1157-1166. [CrossRef]

21. Pérez-Omil, J.A.; Bernal, S.; Calvino, J.J.; Hernández, J.C.; Mira, C.; Rodríguez-Luque, M.P.; Erni, R.; Browning, N.D. Combined HREM and HAADF Scanning Transmission Electron Microscopy: A Powerful Tool for Investigating Structural Changes in Thermally Aged Ceria-Zirconia Mixed Oxides. Chem. Mater. 2005, 17, 4282-4285. [CrossRef]

22. Bunluesin, T.; Gorte, R.J.; Graham, G.W. CO oxidation for the characterization of reducibility in oxygen storage components of three-way automotive catalysts. Appl. Catal. B 1997, 14, 105-115. [CrossRef]

23. Gorte, R.J. Ceria in catalysis: From automotive applications to the water-gas shift reaction. AIChE J. 2010, 56, 1126-1135. [CrossRef]

24. Scheffe, J.R.; Steinfeld, A. Thermodynamic Analysis of Cerium-Based Oxides for Solar Thermochemical Fuel Production. Energy Fuels 2012, 26, 1928-1936. [CrossRef]

25. Manning, P.S.; Sirman, J.D.; Kilner, J.A. Oxygen self-diffusion and surface exchange studies electrolytes having the fluorite structure of oxide. Solid State Ion. 1997, 93, 125-132. [CrossRef]

26. Kamiya, M.; Shimada, E.; Ikuma, Y.; Komatsu, M.; Haneda, H. Intrinsic and Extrinsic Oxygen Diffusion and Surface Exchange Reaction in Cerium Oxide. J. Electrochem. Soc. 2000, 147, 1222-1227. [CrossRef]

27. Katsuki, M.; Wang, S.; Yasumoto, K.; Dokiya, M. The oxygen transport in Gd-doped ceria. Solid State Ion. 2002, 154-155, 589-595. [CrossRef]

28. Stan, M.; Zhu, Y.T.; Jiang, H. Kinetics of oxygen removal from ceria. J. Appl. Phys. 2004, 95, 3358-3361. [CrossRef] 
29. Armstrong, E.N.; Duncan, K.L.; Oh, D.J.; Weaver, J.F.; Wachsman, E.D. Determination of Surface Exchange Coefficients of LSM, LSCF, YSZ, GDC Constituent Materials in Composite SOFC Cathodes. J. Electrochem. Soc. 2011, 158, B492-B499. [CrossRef]

30. Gopal, C.B.; Haile, S.M. An electrical conductivity relaxation study of oxygen transport in samarium doped ceria. J. Mater. Chem. A 2014, 2, 2405-2417. [CrossRef]

31. Rutman, J.; Kilo, M.; Weber, S.; Riess, I. Tracer surface exchange and diffusion of oxygen in nano crystals of Gd doped $\mathrm{CeO}_{2}$. Solid State Ion. 2014, 265, 29-37. [CrossRef]

32. Maier, J. On the correlation of macroscopic and microscopic rate constants in solid state chemistry. Solid State Ion. 1998, 112, 197-228. [CrossRef]

33. Knoblauch, N.; Dörrer, L.; Fielitz, P.; Schmücker, M.; Borchardt, G. Surface controlled reduction kinetics of nominally un-doped polycrystalline $\mathrm{CeO}_{2}$. Phys. Chem. Chem. Phys. 2015, 17, 5849-5860. [CrossRef] [PubMed]

34. Fielitz, P.; Borchardt, G. Oxygen exchange at gas/oxide interfaces: How the apparent activation energy of the surface exchange coefficient depends on the kinetic regime. Phys. Chem. Chem. Phys. 2016, 18, 22031-22038. [CrossRef] [PubMed]

35. Rührup, V.; Wiemhöfer, H. Ionic Conductivity of Gd- and Y-Doped Ceria-Zirconia Solid Solutions. Z. Naturforsch. 2006, 61b, 916-922. [CrossRef]

36. Ji, H.-I.; Davenport, T.C.; Gopal, C.B.; Haile, S.M. Extreme high temperature redox kinetics in ceria: Exploration of the transition from gas-phase to material-kinetic limitations. Phys. Chem. Chem. Phys. 2016, 18, 21554-21561. [CrossRef] [PubMed]

37. Pechini, M.P. Method of Preparing Lead and Alkaline Earth Titanates and Niobates and Coating Method Using the Same to form a Capacitor. U.S. Patent 3.330.697, 11 July 1967.

38. Knoblauch, N.; Simon, H.; Schmücker, M. Chemically induced volume change of $\mathrm{CeO}_{2-\delta}$ and nonstoichiometric phases. Solid State Ion. 2017, 301, 43-52. [CrossRef]

39. Ahrens, L.H. The use of ionization potentials Part 1. Ionic radii of the elements. Geochim. Cosmochim. Acta 1952, 2, 155-169. [CrossRef]

40. Bishop, S.R. Chemical expansion of solid oxide fuel cell materials: A brief overview. Acta Mech. Sin. 2013, 29, 312-317. [CrossRef]

41. Marrocchelli, D.; Bishop, S.R.; Tuller, H.L.; Yildiz, B. Understanding Chemical Expansion in Non-Stoichiometric Oxides: Ceria and Zirconia Case Studies. Adv. Funct. Mater. 2012, 22, 1958-1965. [CrossRef]

42. Hull, S.; Norberg, S.T.; Ahmed, I.; Eriksson, S.G.; Marrocchelli, D.; Madden, P.A. Oxygen vacancy ordering within anion-deficient Ceria. J. Solid State Chem. 2009, 182, 2815-2821. [CrossRef]

43. Schulz, U.; Saruhan, B.; Fritscher, K.; Leyens, C. Review on Advanced EB-PVD Ceramic Topcoats for TBC Applications. Int. J. Appl. Ceram. Technol. 2004, 1, 302-315. [CrossRef]

44. Chen, P.L.; Chen, I.W. Role of Defect Interaction in Boundary Mobility and Cation Diffusivity of CeO 2 . J. Am. Ceram. Soc. 1994, 77, 2289-2297. [CrossRef]

45. Beschnitt, S.; Zacherle, T.; De Souza, R.A. Computational Study of Cation Diffusion in Ceria. J. Phys. Chem. C 2015, 119, 27307-27315. [CrossRef]

46. Kilner, J.A.; De Souza, R.A.; Fullarton, I.C. Surface exchange of oxygen in mixed conducting perovskite oxides. Solid State Ion. 1996, 86-88, 703-709. [CrossRef]

47. Kilner, J.A.; Skinner, S.J.; Brongersma, H.H. The isotope exchange depth profiling (IEDP) technique using SIMS and LEIS. J. Solid State Electrochem. 2011, 15, 861-876. [CrossRef]

48. Blair, J.; Mebane, D.S. A Bayesian approach to electrical conductivity relaxation and isotope exchange/secondary ion mass spectrometry. Solid State Ion. 2015, 270, 47-53. [CrossRef]

49. Ananyev, M.V.; Tropin, E.S.; Eremin, V.A.; Farlenkov, A.S.; Smirnov, A.S.; Kolchugin, A.A.; Porotnikova, N.M.; Khodimchuk, A.V.; Berenov, A.V.; Kurumchin, E.K. Oxygen isotope exchange in $\mathrm{La}_{2} \mathrm{NiO}_{4 \pm \delta}$. Phys. Chem. Chem. Phys. 2016, 18, 9102-9111. [CrossRef] [PubMed]

50. Panlener, R.J.; Blumenthal, R.N.; Garnier, J.E. A Thermodynamic Study of Nonstoichiometric Cerium Dioxide. J. Phys. Chem. Solids 1975, 36, 1213-1222. [CrossRef]

51. Kilner, J.A.; Steele, B.C.H. Oxygen self-diffusion studies using negative-ion secondary ion mass spectrometry (SIMS). Solid State Ion. 1984, 12, 89-97. [CrossRef] 
52. Chater, R.J.; Carter, S.; Kilner, J.A.; Steele, B.C.H. Development of a novel SIMS technique for oxygen self-diffusion and surface exchange coefficient measurements in oxides of high diffusivity. Solid State Ion. 1992, 53-56, 859-867. [CrossRef]

53. Fielitz, P.; Borchardt, G. On the accurate measurement of oxygen self-diffusivities and surface exchange coefficients in oxides via SIMS depth profiling. Solid State Ion. 2001, 144, 71-80. [CrossRef]

54. Crank, J. The Mathematics of Diffusion, 2nd ed.; Oxford University Press: Oxford, UK, 1975.

55. De Souza, R.A.; Zehnpfenning, J.; Martin, M.; Maier, J. Determining oxygen isotope profiles in oxides with Time-of-Flight SIMS. Solid State Ion. 2005, 176, 1465-1471. [CrossRef]

56. De Souza, R.A. A universal empirical expression for the isotope surface exchange coefficients $\left(k^{*}\right)$ of acceptor-doped perovskite and fluorite oxides. Phys. Chem. Chem. Phys. 2006, 8, 890-897. [CrossRef] [PubMed]

57. Boukamp, B.A.; van Hassel, B.A.; Vinke, I.C.; de Vries, K.J.; Burggraaf, A.J. The Oxygen transfer process on oxide/noble metal electrodes, studied with impedance spectroscopy, DC polarization and isotope exchange. Electrochem. Acta 1993, 38, 1817-1825. [CrossRef]

58. Chueh, W.C.; McDaniel, A.H.; Grass, M.E.; Hao, Y.; Jabeen, N.; Liu, Z.; Haile, S.M.; McCarty, K.F.; Bluhm, H.; El Gabaly, F. Highly Enhanced Concentration and Stability of Reactive $\mathrm{Ce}^{3+}$ on Doped $\mathrm{CeO}_{2}$ Surface Revealed In Operando. Chem. Mater. 2012, 24, 1876-1882. [CrossRef]

59. Murugan, B.; Ramaswamy, A.V. Defect-Site Promoted Surface Reorganization in Nanocrystalline Ceria for the Low-Temperature Activation of Ethylbenzene. J. Am. Chem. Soc. 2007, 129, 3062-3063. [CrossRef] [PubMed]

60. Nolan, M.; Parker, S.C.; Watson, G.W. $\mathrm{CeO}_{2}$ catalysed conversion of $\mathrm{CO}, \mathrm{NO}_{2}$ and $\mathrm{NO}$ from first principles energetics. Phys. Chem. Chem. Phys. 2006, 8, 216-218. [CrossRef] [PubMed]

61. Sayle, T.X.T.; Parker, S.C.; Catlow, R.A. Surface Oxygen Vacancy Formation on $\mathrm{CeO}_{2}$ and Its Role in the Oxidation of Carbon Monoxide. J. Chem. Soc. Chem. Commun. 1992, 977-978. [CrossRef]

62. Fleig, J. On the current-voltage characteristics of charge transfer reactions at mixed conducting electrodes on solid electrolytes. Phys. Chem. Chem. Phys. 2005, 7, 2027-2037. [CrossRef] [PubMed]

63. Bale, C.W.; Bélisle, E. Available online: http://www.crct.polymtl.ca/equiweb.php (accessed on 7 August 2016).

64. Bevan, D.J.M.; Kordis, J. Mixed Oxides Of The Type $\mathrm{MO}_{2}$ (Fluorite)- $\mathrm{M}_{2} \mathrm{O}_{3}-\mathrm{I}$ Oxygen Dissociation Pressures And Phase Relationships In The System $\mathrm{CeO}_{2}-\mathrm{Ce}_{2} \mathrm{O}_{3}$ At High Temperatures. J. Inorg. Nucl. Chem. 1964, 26, 1509-1523. [CrossRef]

65. Bueno-López, A.; Krishna, K.; Makkee, M. Oxygen exchange mechanism between isotopic $\mathrm{CO}_{2}$ and $\mathrm{Pt} / \mathrm{CeO}$. Appl. Catal. A Gen. 2008, 342, 144-149. [CrossRef]

66. Jones, J.; Xiong, H.; DeLaRiva, A.T.; Peterson, E.J.; Pham, H.; Challa, S.R.; Qi, G.; Oh, S.; Wiebenga, M.H.; Hernández, X.I.P.; et al. Thermally stable single-atom platinum-on-ceria catalysts via atom trapping. Science 2016, 353, 150-154. [CrossRef] [PubMed]

67. Merkle, R.; Maier, J. How Is Oxygen Incorporated into Oxides? A Comprehensive Kinetic Study of a Simple Solid-State Reaction with $\mathrm{SrTiO}_{3}$ as a Model Material. Angew. Chem. Int. Ed. 2008, 47, 3874-3894. [CrossRef] [PubMed]

68. Maier, J. Interaction of oxygen with oxides: How to interpret measured effective rate constants? Solid State Ion. 2000, 135, 575-588. [CrossRef]

69. Armstrong, E.N.; Duncan, K.L.; Wachsman, E.D. Effect of A and B-site cations on surface exchange coefficient for $\mathrm{ABO}_{3}$ perovskite materials. Phys. Chem. Chem. Phys. 2013, 15, 2298-2308. [CrossRef] [PubMed]

70. Carslaw, H.S.; Jaeger, J.C. Conduction of Heat in Solids, 2nd ed.; Clarendon Press: Wotton-under-Edge, UK, 1959.

(C) 2017 by the authors. Licensee MDPI, Basel, Switzerland. This article is an open access article distributed under the terms and conditions of the Creative Commons Attribution (CC BY) license (http:/ / creativecommons.org/licenses/by/4.0/). 